



\section{VACINAS: \\ CENÁRIO HISTÓRICO E IMPORTÂNCIA COMO \\ MEDIDA ESSENCIAL NO ENFRENTAMENTO \\ DAS PANDEMIAS}

Editor Chefe

Msc Washington Moreira Cavalcanti

Autores

Ágatha Cristina Moraes Campos Alex Campos de Aguiar Alice Ribeiro de Sousa Ana Beatriz Lima dos Santos Amanda Dantas Temoteo Beatriz de Sousa Campos Emilly dos Santos de Oliveira Isael de Oliveira Silva Joyce Ferreira de Oliveira Rocha Keilla Barbosa de Souza Leide Sara Pires Pereira Nathalia dos Santos Melo Natiele Palmeira da Silva

Sarah Emily Borges Pereira Thais da Silva Rodrigues

Thais Ranielle Souza de Oliveira

Conselho Editorial

Msc Lais Brito Cangussu

Msc Rômulo Maziero

Msc Jorge dos Santos Mariano

Dr Jean Canestri

Projeto Gráfico e Diagramação Departamento de arte Synapse Editora

Edição de Arte Maria Aparecida Fernandes

Revisão Os Autores
2021 by Synapse Editora

Copyright (C) Synapse Editora

Copyright do Texto (c) 2021 Os autores

Copyright da Edição (c) 2021 Synapse Editora

Direitos para esta edição cedidos à

Synapse Editora pelos autores.

Todo o texto bem como seus elementos, metodologia, dados apurados e a correção são de inteira responsabilidade dos autores. Estes textos não representam de forma alusiva ou efetiva a posição oficial da Synapse Editora.

A Synapse Editora não se responsabiliza por eventuais mudanças ocorridas nos endereços convencionais ou eletrônicos citados nesta obra.

Os livros editados pela Synapse Editora, por serem de acesso livre, Open Access, é autorizado o download da obra, bem como o seu compartilhamento, respeitando que sejam referenciados os créditos autorais. Não é permitido que a obra seja alterada de nenhuma forma ou usada para fins comerciais.

O Conselho Editorial e pareceristas convidados analisaram previamente todos os manuscritos que foram submetidos à avaliação pelos autores, tendo sido aprovados para a publicação.

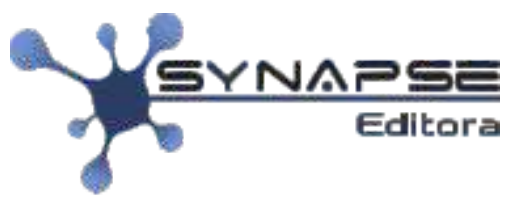

Compartillhando conhecimento 


\section{VACINAS: \\ CENÁRIO HISTÓRICO E IMPORTÂNCIA COMO \\ MEDIDA ESSENCIAL NO ENFRENTAMENTO \\ DAS PANDEMIAS}

\section{O48v Oliveira, Thais Ranielle Souza de}

Vacinas: Cenário histórico e importância como medida essencial no enfrentamento das pandemias

Autores: Ágatha Cristina Moraes Campos, Alex Campos de Aguiar Alice Ribeiro de Sousa, Ana Beatriz Lima dos Santos, Amanda Dantas Temoteo, Beatriz de Sousa Campos, Emilly dos Santos de Oliveira, Isael de Oliveira Silva, Joyce Ferreira de Oliveira Rocha,

Keilla Barbosa de Souza, Leide Sara Pires Pereira, Nathalia dos Santos Melo, Natiele Palmeira da Silva, Sarah Emily Borges Pereira, Thais da Silva Rodrigues, Thais Ranielle Souza de Oliveira.

Belo Horizonte, MG: Synapse Editora, 2021, 65 p.

Formato: PDF

Modo de acesso: World Wide Web

Inclui bibliografia

ISBN: 978-65-88890-15-8

DOI: doi.org/10.36599/editpa-2021_chimep

1. Vacinas, 2. Medicina preventiva, 3. Enfrentamento das Pandemias,

4. Vacinação, 6. Imunização.

I. Pré-processamento e segmentação de palavras manuscritas utilizando técnicas de processamento de imagens

SYNAPSE EDITORA

Belo Horizonte - Minas Gerais

CNPJ: 20.874.438/0001-06

Tel: + 5531 98264-1586

www.editorasynapse.org

editorasynapse@gmail.com

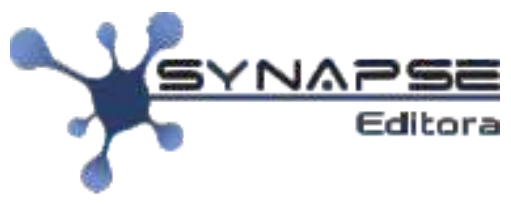

Compartillhando conhecimento

2021 


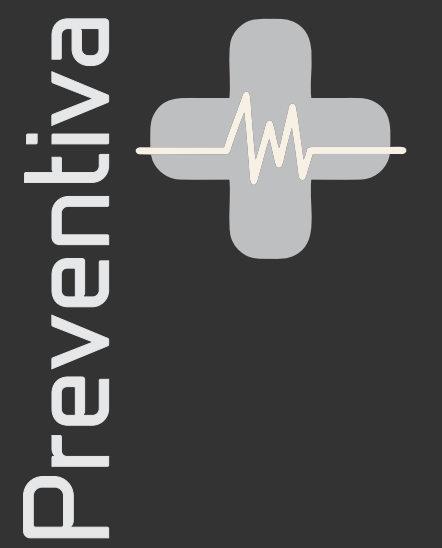

\section{Apresentação}

Em 2020 o mundo se deparou com uma nova pandemia provocada pelo SARS-CoV-2 causando a COVID-19. Uma nova doença e grandes desafios a serem enfrentados, como vencer esse inimigo invisível? Cientistas e governantes estavam diante desse grande problema de saúde pública. Em pouco tempo a doença se alastrou pelo mundo causando milhares de óbitos. Por outro lado, em um grande esforço mundial cientistas começaram as pesquisas para o desenvolvimento de vacinas e pela primeira vez na história em tempo recorde ainda em 2020 foram desenvolvidas as primeiras vacinas contra a COVID-19.

Assim ficou demonstrado que a ciência é uma grande aliada histórica da saúde coletiva. Lamentavelmente um contraponto a ciência é o negacionismo que ganhou grande força com a disseminação de fakes news e o descrédito na segurança e eficácia das vacinas colocando em xeque um grande esforço mundial para frear essa pandemia.

Diante essa realidade, surgiu a ideia dessa obra como uma viagem no tempo mostrando o quanto a ciência e as vacinas mudaram a perspectiva de sobrevivência relacionada a doenças infectocontagiosas. Assim, esperamos trazer ao leitor essa noção relembrando todas as conquistas da população humana graças as vacinas. Da origem das pandemias até as vacinas atuais a ciência celebra a vida.

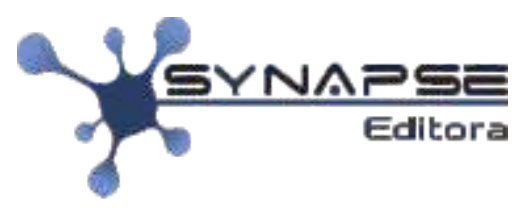

Compartillhando conhecimento 리기 


\section{Sumário}

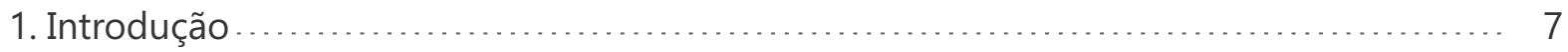

2. Levantamento das grandes pandemias com foco nos séculos XX e XXI $\ldots \ldots \ldots \ldots \ldots . . . . . . .9$

2.1 Gripe Espanhola ............................................................. 10

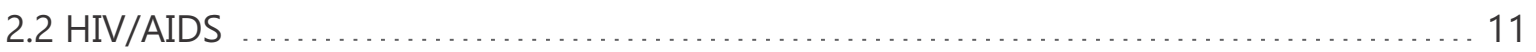

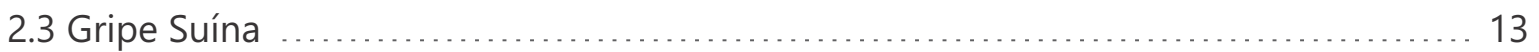

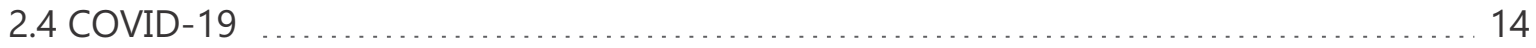

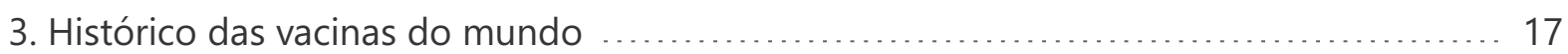

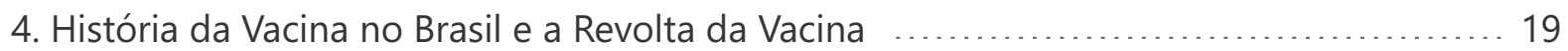

5. As primeiras grandes campanhas de imunização no Brasil .......................... 21

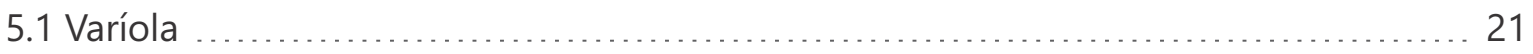

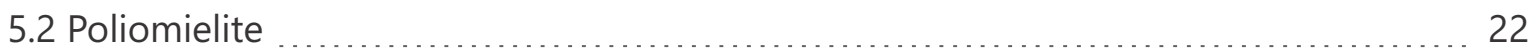

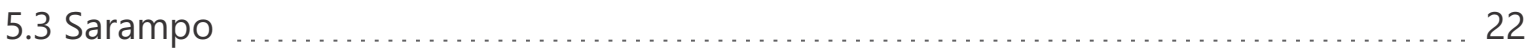

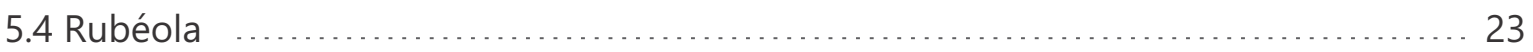

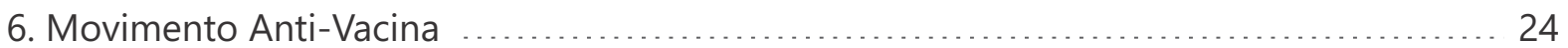

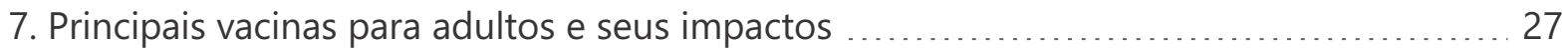

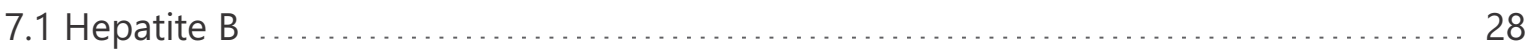

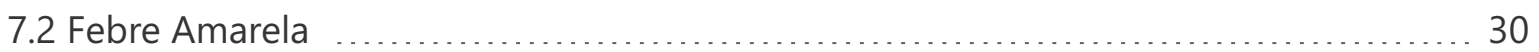

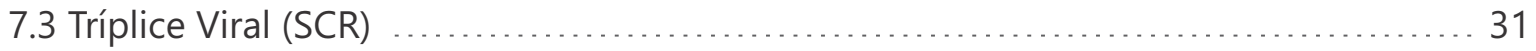

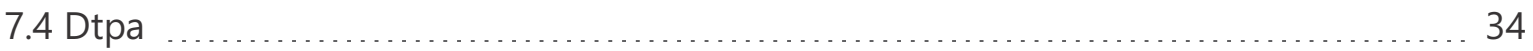

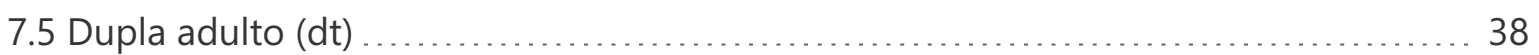

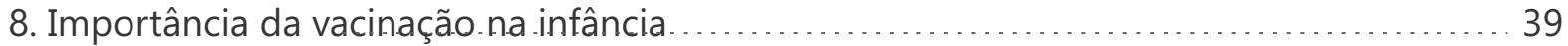

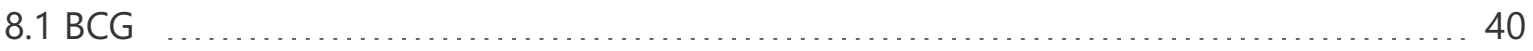

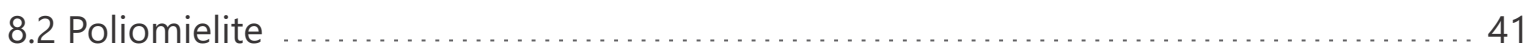

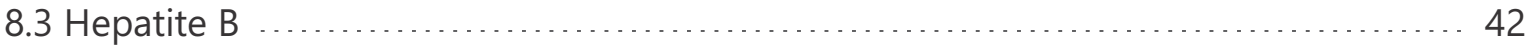

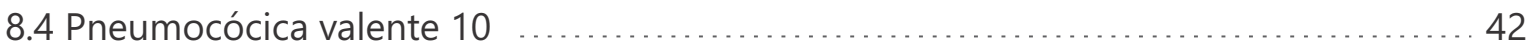

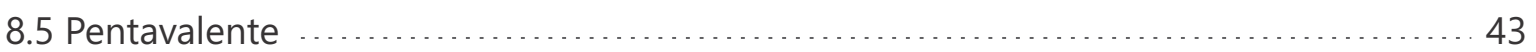

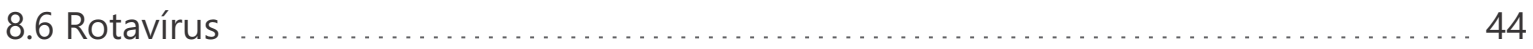

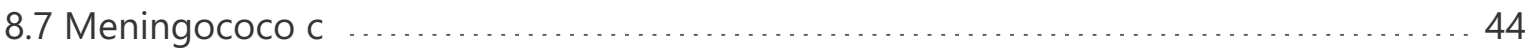

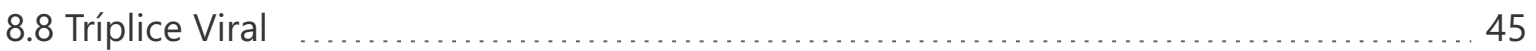

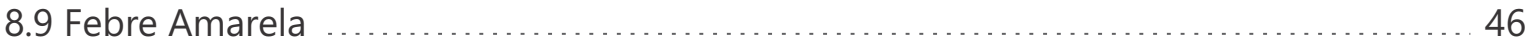

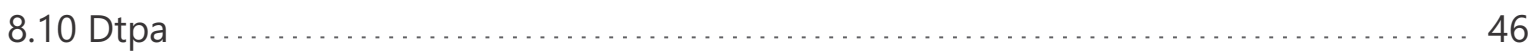

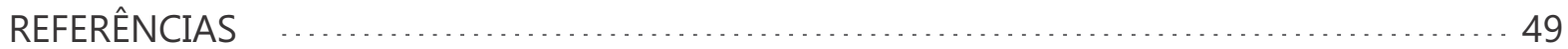




\section{Capítulo1}

\section{INTRODUÇÃO}

o longo da história, surgiram doenças com o potencial de exterminar populações através da sua rápida propagação, desta forma esses agravos logo se disseminaram pelo mundo transformando-se em pandemias dizimando a vida de grandes populações.

Historicamente a vacinação é conhecida como uma estratégia eficaz contra os agentes causadores de doenças com potencial pandêmico diminuindo assim a mortalidade. A primeira vacina foi criada pelo médico inglês Edward Jenner em 1796, protegia contra o vírus da varíola, e, se tornou um dos mais importantes avanços da medicina.

A vacina é capaz de conter a propagação de um agente infeccioso através do desenvolvimento de uma resposta imune no indivíduo que a recebe. Sabemos que no atual cenário da pandemia da COVID-19 a discussão a respeito da importância da vacinação ganhou ainda mais destaque, em contrapartida, os movimentos anti-vacinas aliados às fake news constantemente publicadas em redes sociais vêm ganhando visibilidade através de discursos infundados e sem comprovação científica.

O Brasil dispõe de um calendário infantil de vacinação que conta com vacinas obrigatórias distribuídas gratuitamente pelo Sistema Único de Saúde (SUS) nas Unidades Básicas de Saúde (UBS), assim o ato de não vacinar pode resultar em consequências graves para a saúde pública, como a volta de doenças erradicadas, surgimento de epidemias/pandemias e 
aumento da taxa de mortalidade que desde a introdução da vacina sofre queda relativa.

Diante o exposto, nosso objetivo como componentes do Projeto de Extensão Estratégias de Promoção a Saúde e Prevenção de Doenças do UNIEURO, é demonstrar através desse ebook a vacina como uma estratégia eficaz de prevenção de grande impacto na qualidade de vida da população e importância nas diferentes fases da vida. 


\section{Capítulo2}

\section{LEVANTAMENTO DAS \\ GRANDES PANDEMIAS NO MUNDO COM FOCO NOS SÉCULOS XX E XXI}

ntende-se por pandemia a disseminação mundial de uma nova doença, ou seja, é quando uma epidemia, surto que afeta uma região, se espalha por diferentes continentes com transmissão sustentada de pessoa para pessoa (FIOCRUZ, 2020).

No período de 541 e 750 d.C., surgiram ondas epidêmicas por todo o mundo antigo atingindo toda a população, denominada praga do Justiniano. A doença era causada pelas pulgas dos ratos trazidos pelas embarcações. Em decorrência da doença morreram entre 25 e 100 milhões de pessoas (UOL, 2020).

A pandemia de peste negra foi a mais mortífera, estima-se que entre 1347 e 1351 ocorreram de 75 a 200 milhões de mortes, correspondendo a quase um terço da população europeia. A bactéria causadora tinha seu habitat no intestino dos ratos que infestavam as embarcações (UOL, 2013). A falta de higiene pessoal e de conhecimento médico ajudou para a dispersão da doença entre as pessoas (GALILEU, 2020).

No ano de 1520, surge a pandemia de varíola. O agente etiológico não era conhecido, porém várias medidas de controle foram utilizadas, como isolamento, quarentena, variolação e imunização. A vacina contra a varíola foi descoberta pelo médico inglês Edward Jenner no século XVIII sendo um dos mais importantes avanços da medicina e para a imunização em massa (TOLEDO, 2004). Esse vírus com grande impacto na humanidade ocasionou a morte de 300 milhões de pessoas (OSWALDO CRUZ, 2020). 
Ao longo da história surgiram outras pandemias, com especial destaque para as que aconteceram entre os séculos XX (gripe espanhola e a AIDS) e no século XXI (gripe suína e COVID-19). A pandemia da COVID-19 até a presente data desta publicação continua em vigor. Todas essas doenças alteraram completamente cenários em todo o mundo, refletidos significativamente no número de mortes.

\subsection{GRIPE ESPANHOLA}

Atualmente vivencia-se um período pandêmico que afeta todo o mundo, refletindo diretamente na qualidade de vida, direitos humanos, economia, política e outros assuntos importantes. Desta forma é imprescindível buscar compreender a origem e o desenvolvimento de uma pandemia (LIMA, 2009).

Em meados dos anos 1918 e 1919, durante a primeira guerra mundial surgiu uma grande pandemia denominada gripe espanhola. Essa doença provocou o maior índice de mortes do século XX. O primeiro caso confirmado da gripe foi registrado nos Estados Unidos e não demorou muito para atingir a Europa (ATLASHISTÓRICO DO BRASIL, 2016).

A doença foi causada pelo vírus da influenza H1N1, transmitido de pessoa para pessoa, por meio de espirros e tosse, tornando o indivíduo exposto a milhares de partículas virais. A doença afetava a maior parte do trato respiratório e consequentemente o indivíduo evoluía a óbito devido as complicações pulmonares e falta de oxigenação. Essa pandemia ocorreu em duas ondas distintas em relação a gravidade (FIOCRUZ, 2002).

A primeira onda apresentou uma fase altamente contagiosa nos Estados Unidos e toda a Europa, causando febre e mal-estar, com poucas mortes. A segunda onda foi a fase mortal da doença se espalhando por todo o mundo, contaminando diversos países e continentes. Estudos apontam que os números de óbitos devido à pandemia da gripe espanhola variaram entre 20 e 40 milhões (FIOCRUZ, 2002).

No Brasil, os primeiros casos da doença surgiram após a chegada de navios oriundos da Europa, em setembro de 1918. As primeiras cidades afetadas 
foram Recife, Rio de Janeiro e Salvador, atingindo logo após a cidade de São Paulo. Muitos jornais da época espalhavam receitas como forma de prevenção à disseminação aérea do vírus entre estes, à queima do tabaco e incensos, para evitar um maior contágio (FIOCRUZ, 2002).

As autoridades governamentais, não tinham conhecimento da doença, e das formas de tratamento, mas tomaram medidas de prevenção alertando a população a entrar em estado de isolamento social e evitar aglomerações. No entanto, ao longo do período pandêmico foram confirmadas mais de 35 mil mortes por todo o Brasil, e $1 / 4$ das mortes foram admitidas somente no estado do Rio de Janeiro (ATLAS HISTÓRICO DO BRASIL, 2016).

Ainda no ano de 1918, Carlos Chagas assumiu a diretoria do Instituto Oswaldo Cruz e com isso obteve um papel muito importante nesse período por meio de suas pesquisas e todo o seu projeto. Devido à grande insistência da sua parte juntamente ao governo, foi autorizado a impor medidas de saúde pública, como a notificação compulsória dos casos, quarentena de navios, hospitais emergenciais, postos de atendimentos, fechamento de escolas e teatros (FIOCRUZ, 2006).

Por fim, a pandemia gerou mudanças em diversos cenários mundiais principalmente na saúde e setores hospitalares. Até hoje existem questionamentos sobre a origem concreta da gripe e conflitos relacionados a mutações de cepas do vírus e possíveis contaminações futuras.

\subsection{HIV/AIDS}

No ano de 1981, o CDC (Centro para Controle de Doenças) dos Estados Unidos, reconheceu a AIDS (Síndrome da Imunodeficiência Adquirida) como uma doença infecciosa causada pelo vírus HIV que deprime o sistema imunológico e o impede de executar suas funções fisiológicas (FIOCRUZ, 2021). Em contrapartida estudos retrospectivos clínicos epidemiológicos com dados de 1960, reconheceram a presença da doença em homossexuais do sexo masculino na África Equatorial, graças à presença de algum tipo de pneumonia e outras doenças oportunistas (PINTO et al, 2007). A origem do vírus HIV ainda é controversa, há relatos sobre o surgimento na África, sendo sua transmissão de macacos para o homem, no entanto, estes mecanismos seguem sem uma explicação plausível (FORATTINI, 1993). 
No decorrer da epidemia da AIDS pesquisadores observaram fatores que evidenciam a transmissão do HIV. Apesar das singularidades da epidemia em cada local é possível observar fatores em comum entre: a África, Ásia, América Latina e Caribe. Nessas regiões o principal aspecto em comum era o subdesenvolvimento econômico, fazendo trabalhadores se deslocarem das suas cidades para grandes metrópoles devido a uma maior oferta de trabalho permitindo trocas econômicas-sexuais. Posteriormente ao retornarem para seus lares transmitiam o vírus (PARKER et al., 2000).

Com o avanço das pesquisas científicas ficou comprovado que a doença não pertencia somente a homossexuais do sexo masculino, uma vez que casais heterossexuais estavam sendo diagnosticados, iniciando assim a discussão sobre sua via de contágio (PINTO et al., 2007).

Após seu reconhecimento pelo CDC, essa pandemia se tornou a doença infecciosa que mais matava no mundo, atingindo o marco de 690 mil mortes por doenças associadas a AIDS e cerca de 75,7 milhões de pessoas foram infectadas pelo HIV desde o início da epidemia. Segundo a UNAIDS (Programa Conjunto Nações Unidas sobre HIV/Aids) no ano de 1990 foi reportado à OMS (Organização Mundial da Saúde) 307 mil casos de AIDS, no entanto as estimativas eram de números próximos a 1 milhão (UNAIDS, 2020). Depois disso, as suas formas de contágios eram claras assim como suas formas de prevenção (BIBLIOTECA VIRTUAL EM SAÚDE, 2020).

Em relação ao tratamento no ano de 1982 surgiu o AZT (zidovudina), o primeiro medicamento que atuava inibindo a multiplicação do HIV, mas somente no ano de 1992 o Ministério da Saúde liberou o uso do mesmo no Brasil. A distribuição do medicamento foi realizada por intermédio do SUS (Sistema Único de Saúde) reduzindo a incidência de mortalidade em 50\% e melhorando a qualidade de vida do portador de HIV/Aids (PINTO et al, 2007). Com o passar dos anos novos medicamentos surgiram melhorando o prognóstico e a qualidade de vida dos portadores de HIV, de acordo a UNAIDS (Programa Conjunto das Nações Unidas sobre HIV/Aids) 25,4 milhões de pessoas tem acesso aos ARV (antirretrovirais) (UNAIDS, 2020). 


\subsection{Gripe suína}

Desde a primeira pandemia até os dias atuais, sabemos que o mundo não é mais o mesmo. De fato, muitos avanços científicos foram alcançados, com isso adquirimos vacinas, medicamentos, materiais de proteção entre outros complementos. Mas vale ressaltar que é incerta a aposta de que todos esses avanços podem assegurar uma proteção total a humanidade, ainda mais quando estamos expostos a vírus e suas possíveis mutações (MANUAL MSD, 2020).

Abordamos anteriormente sobre a pandemia de gripe espanhola em 1918, ter sido causada pelo vírus da Influenza A, o que gerou muitas dúvidas sobre novas cepas e uma possível contaminação no futuro. Precisamente em março de 2009, no México surgiu um surto causado pelo vírus H1N1, era uma nova cepa do vírus Influenza A. Muitos denominaram a doença como gripe mexicana, gripe A e gripe suína (FIOCRUZ, 2021).

A sintomatologia da doença é similar a outras gripes e doenças que afeta o trato respiratório, como: febre, tosse, diarreia, dor muscular e outros sintomas. A forma de transmissão, que nem sempre ocorre no período dos sintomas, basicamente se dá por meio do contato com a pessoa infectada ou contato com objetos contaminados e por meio de partículas virais expostas no ambiente aéreo (MANUAL MSD, 2020).

A doença se alastrou rapidamente por diversas partes do mundo, contaminando América do Norte, Europa e toda Oceania, assim em abril de 2009 foi decretado estado de emergência na saúde pública internacional pela OMS. (FIOCRUZ, 2021).

No Brasil, em maio de 2009 a doença atingiu a princípio as regiões sul e sudeste, não demorou muito e logo se espalhou por todo o país. O primeiro caso de óbito confirmado ocorreu no estado do Rio Grande do Sul. Na época o governo federal liberou mais de 2,1 bilhões de reais para produção de vacinas, materiais hospitalares e ampliação de UTIs. A produção de vacinas contra H1N1 foi iniciada no segundo semestre de 2009 atingindo um total 83 milhões de doses (FIOCRUZ, 2021).

Campanha de vacinação teve início em março de 2010. As primeiras doses foram destinadas as pessoas com estado de saúde crítico e aos idosos do 
grupo de risco. O Brasil foi um dos países que mais vacinou pessoas na época, chegando a $42 \%$ da população imunizada, em aproximadamente três meses foram 92 milhões de pessoas vacinadas. O país alcançou a meta de $88 \%$ de idosos do grupo de risco imunizados (FIOCRUZ, 2021).

Segundo dados epidemiológicos no ano de 2009, 60 mil pessoas foram infectadas e 2.146 morreram devido à doença. Após a vacinação no ano seguinte o Brasil apresentou baixo no número de mortes, chegando a 100 casos (FIOCRUZ, 2021).

\subsection{COVID-19}

Os Coronavírus, são vírus pertencentes à família coronaviridae e podem causar infecções respiratórias. Foram isolados pela primeira vez em 1937 e só em 1965 receberam essa denominação. No ano de 2019, foi descrito um novo tipo, o SARS-CoV-2 como agente etiológico de uma possível nova doença após o aparecimento de casos na cidade de Wuhan, na China. Em 2020 os casos se alastraram saindo da China e alcançando outros continentes, essa nova doença foi denominada COVID-19. Diante este cenário a OMS (Organização Mundial da Saúde) decretou a pandemia da COVID-19, sendo o SARS-CoV-2 o causador dessa doença (LIMA, 2020; CAVALCANTE et al., 2020)

Por ser um vírus que tem o ciclo principal de transmissão através das vias aéreas é também classificado como um vírus respiratório. O contágio ocorre de pessoa para pessoa, através de gotículas (diâmetro $>5 \mu \mathrm{m}$ ) e aerossóis (diâmetro $<5 \mu \mathrm{m}$ ) expelidos no ambiente pela boca e nariz de indivíduos contaminados ao tossir, falar, espirrar e até ao respirar (FRANCO et al., 2020).

Por acometer principalmente o pulmão, a COVID-19 é classificada atualmente como uma síndrome respiratória altamente contagiosa, apresentando um amplo aspecto clínico infeccioso, variando de um simples resfriado até uma pneumonia grave ou em outros casos, apresentar-se de forma assintomática. Quando apresenta sintomas, os mais frequentes são: febre, tosse, dor no corpo, mal-estar, dor de garganta, fadiga, dispneia leve, dor de cabeça e congestão nasal, e em alguns casos, com menor frequência pode apresentar diarreia, náusea e vômito (ISER et al., 2020; FRANCO et al., 2020). 
As medidas de prevenção orientadas pelo Ministério da Saúde estão fundamentadas nessas características de transmissão, o que reforça a importância de adotá-las frente a pandemia. As medidas envolvem uso de máscaras, a lavagem das mãos com água e sabão ou sua higienização com álcool em gel; cobrir o nariz e a boca ao espirrar ou tossir; o distanciamento social; o não compartilhamento de objetos de uso pessoal, como copos e talheres; e o hábito de se manter a ventilação nos ambientes (OLIVEIRA et al., 2020).

No início da pandemia contava-se apenas com as medidas de prevenção disponíveis na tentativa de conter o avanço desta doença, no entanto, cientistas começaram as pesquisas para o desenvolvimento de vacinas, sendo contabilizado ao redor do mundo um total de 165 possíveis vacinas que poderiam ser desenvolvidas com o avançar do conhecimento tecnológico e científico sobre o vírus e a doença (UNASUS, 2020). De acordo a OMS (Organização Mundial da Saúde) muitas das tentativas foram frustradas fundamentando-se nos erros comuns e nas dificuldades que enfrentaram, ficando apenas na primeira fase de teste (FIOCRUZ, 2020).

Quando se trata da produção em larga escala de uma vacina, existem etapas a serem desenvolvidas e estas são divididas em três fases. Na primeira fase o objetivo é garantir a segurança do produto quanto a toxicidade e a ocorrência de efeitos adversos, envolvendo nesse primeiro momento de teste entre $20 \mathrm{e}$ 100 pessoas, geralmente adultos saudáveis. Na segunda fase se verifica a imunogenicidade, ou seja, a capacidade que a vacina tem de estimular o sistema imunológico a produzir anticorpos; nesta fase geralmente são incluídas acima de 100 pessoas para a realização do teste. Na terceira e última etapa a vacina é testada em milhares de pessoas para averiguar sua eficácia (FIOCRUZ, 2020).

Desde 2020 a meta era a efetivação de uma vacina que cause o mínimo de efeito adverso e tenha o efeito protetivo esperado (FIOCRUZ, 2020). Essa mobilização mundial voltada a pesquisa para produção de vacinas gerou até a presente data a viabilização de 6 imunizantes na terceira fase. Por ordem de eficácia temos a Pfizer/BioNTech ${ }^{\circledR}$ (95\%) produzida pela farmacêutica americana Pfizer em parceria com a empresa alemã BioNTech. Em seguida a Moderna $^{\circledR}(94,1 \%)$, desenvolvida pela farmacêutica também americana Moderna. Em terceiro lugar aparece a Sputnik $V^{\circledR}(91,6 \%)$, desenvolvida pelo Instituto Gamaleya de Pesquisa da Rússia. Na quarta posição está a 
Oxford/AstraZeneca ${ }^{\circledR}(70 \%)$, desenvolvida no Reino Unido em uma parceria entre a Universidade de Oxford e a farmacêutica AstraZeneca (UOL, 2021).

No Brasil, houve a transferência de tecnologia para Bio-Manguinhos, a unidade produtora de imunobiológicos da Fiocruz para a produção da Oxford/AstraZeneca ${ }^{\circledR}$. Outra vacina em produção no país é a CoronaVac ${ }^{\circledR}$, vacina criada pela farmacêutica chinesa Sinovac e com parceria na transferência de tecnologia para a produção pelo Instituto Butantan. Essa vacina apresenta eficácia global de $50,38 \%$, ou seja, os vacinados têm $50,38 \%$ menos risco de adoecer e, caso desenvolva a COVID-19, a vacina oferece $100 \%$ de eficácia para não evolução de um quadro grave e $78 \%$ na prevenção de casos leves. Todas as vacinas citadas anteriormente são administradas em 2 doses, no entanto a vacina produzida pela farmacêutica Janssen, da companhia Johnson \& Johnson ${ }^{\circledR}$, diferente das outras, é aplicada em dose única com eficácia global de 66\% (UOL, 2021).

A imunização em nível global ainda é desigual e lenta, por isso as medidas de prevenção não devem ser abandonadas. Infelizmente, o atual cenário da pandemia da COVID-19 apresenta grandes danos traduzidos em perda de vidas, mudanças de rotinas, problemas na economia e grandes impactos sociais. Até a presente data (01 de maio de 2021), foram registrados 151 milhões de casos confirmados no mundo (FIOCRUZ, 2021). 


\section{Capítulo3}

\section{HISTÓRICO DAS VACINAS NO MUNDO}

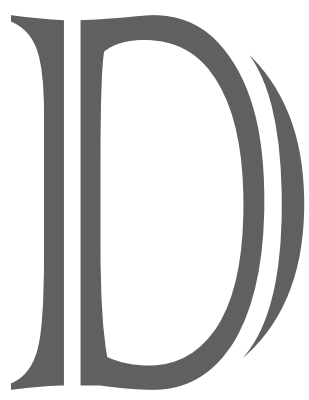

urante toda a história, surgiram doenças com a capacidade de dizimar populações. Uma forma para reduzir o impacto dessas doenças é buscando estratégias preventivas, o que impulsionou a criação das vacinas (LARROCA; CARRARO, 2000).

A varíola foi uma das doenças que assolaram a população mundial, uma doença infectocontagiosa viral extremamente grave que causa hipertermia, cefaleia, mal-estar, mialgias, prurido, lesões na pele, entre outros, podendo levar o indivíduo à morte. $\mathrm{O}$ contágio se dá através da inalação de gotículas contendo o vírus que são expelidas pela mucosa oral, nasal ou faríngea (LEVI; KALLÁS, 2002).

Registros escritos do século XVI documentam na China a prática da técnica de variolação, que consistia na retirada de material das pústulas de um indivíduo doente e a posterior administração na pele ou narinas daqueles que buscavam se proteger. A técnica logo se difundiu pela Inglaterra e motivou a primeira campanha obrigatória de imunização no ano de 1777, quando George Washington determinou que todos os soldados que lutavam na guerra de independência do EUA deveriam passar pela variolação. A prática gerava imunidade, mas não é tão segura como a vacinação (TOLEDO, 2003). 
Diante disso, era necessário descobrir como imunizar uma grande população contra a varíola. Em 1796, o médico Edward Jenner associou as informações científicas existentes e observou que os trabalhadores da zona rural contraiam uma forma mais moderada da varíola por ter tido contato com a varíola bovina (Varíola Vaccinae), ele decidiu então usar as duas formas do vírus para inocular uma criança, que posteriormente não desenvolveu os sintomas (BIO - MANGUNHOS/FIOCRUZ, 2019).

Surgem então, em 1803, as campanhas de vacinação gratuitas com intuito de reduzir a mortalidade. Em 1840, o governo britânico proíbe a variolação e determina que a vacina seja fornecida para todos que desejassem. Em 1853, a imunização para crianças foi instituída e consequentemente aumentando de forma significativa à expectativa de vida no Reino Unido (FIGUEIREDO, 2021).

No final do século XIX, com a Segunda Revolução Industrial, a fabricação de vacinas já estava difundida por diversos países. Novas vacinas foram desenvolvidas para outras doenças como carbúnculo e raiva, ocorrendo também a melhoria dos imunizantes já existentes. Tendo como principal cientista desse período o biólogo Luis Pasteur, um grande defensor da tese de que grande parte das doenças contagiosas e dos processos infecciosos ocorria devido à ação de microrganismos (FERNANDES, 2003). 


\section{Capítulo4}

\section{História da Vacina no Brasil e a REVOLTA DA VACINA}

or volta do ano de 1900, Cesário Alvim, prefeito do Rio de Janeiro, capital do Brasil, reconhece a necessidade da produção de soros contra a peste bubônica para combater a epidemia que assolava a região na época. Surge então o Instituto Soroterápico Federal localizado em Manguinhos, Inhaúma, sob direção técnica do médico Oswaldo Cruz.

Em 1903, o médico é nomeado pelo presidente Rodrigues Alves como Diretor Geral de Saúde Pública e assume o cargo com a missão de realizar uma reforma sanitária na capital, com foco no combate à febre amarela, peste bubônica e varíola (FIOCRUZ, 2005).

Em 1904, o Brasil se depara com um surgimento de muitos casos de varíola, registrando, aproximadamente, seis mil casos. Diante desse aumento, Oswaldo Cruz apresenta um projeto de lei com regras rígidas para a obrigatoriedade da vacinação no Brasil, causando assim muitos debates. A lei foi aprovada e antecipou uma revolta que mobilizou diversas classes sociais, conhecida como a revolta da vacina (HOCHMAN, 2011). 
A revolta da vacina em 1904 foi um momento turbulento que provocou a paralização da cidade do Rio de janeiro. As informações sobre a importância e benefício da vacinação eram apenas de conhecimento médico, ainda não havia campanhas de imunização. A obrigação de se render à aplicação de um líquido estranho no corpo e o regime autoritário imposto pela lei, causou uma grande resistência na sociedade, provocando uma reação policial violenta, que resultou em prisões, deportações, feridos e mortos (VANIFAS et al. 2013). Diante essa situação, o presidente Rodrigues Alves revoga a obrigatoriedade (FIOCRUZ, 2005). 


\section{Capítulo5}

\section{AS PRIMEIRAS GRANDES CAMPANHAS DE IMUNIZAÇÃO NO BRASIL}

Sabemos que a vacinação é a caminho mais eficaz para a proteção contra inúmeras doenças bem como na diminuição dos sintomas. $\mathrm{O}$ Programa Nacional de Imunizações (PNI) do Brasil é reconhecido mundialmente como referência de saúde pública desde 1973.

\subsection{Varíola}

Em 1962, o governo brasileiro organizou a Campanha Nacional contra a Varíola, porém, através do decreto no 59.153 de 1966, a antiga campanha foi substituída e passou a ser reconhecida como Campanha de Erradicação da Varíola. (REVISTA DA VACINA, 2017).

A campanha criada compreendia quatro fases, sendo uma dessas a vacinação em massa da população. Para que fosse possível alcançar quase $100 \%$ da população, utilizava-se o injetor de pressão para a aplicação da vacina, o que garantia a vacinação de muitas pessoas em um curto espaço de tempo (REVISTA DA VACINA, 2017). Finalizou-se em 1973, abrindo caminhos para o surgimento do Plano Nacional de Imunização, a campanha foi um marco e garantiu ao Brasil a certificação de erradicação da varíola em 1980 (TEMPORÃO 2003). 


\subsection{Poliomielite}

Em 1971, ocorreu a primeira tentativa de conter a poliomielite no Brasil, através da instituição do Plano Nacional de Controle da Poliomielite pelo Ministério da Saúde, em consequência dos vários surtos da doença no país (REVISTA DA VACINA, 2017).

A criação dos "Dias Nacionais de Vacinação" tinha como objetivo a imunização de crianças de 0 a 5 anos em um único dia. Esta iniciativa foi eficaz e promoveu uma redução significativa dos casos de poliomielite (REVISTA DA VACINA, 2017). A campanha de vacinação ocorre todos os anos em duas etapas em todo o país desde 1980, mas somente em 1994 o Brasil recebeu a certificação internacional da erradicação da doença (REVISTA DA VACINA, 2017).

\subsection{Sarampo}

A primeira tentativa de conter o surto de sarampo no Brasil ocorreu em 1992, com a realização da campanha de vacinação para crianças com idade entre 9 meses e 14 anos, independentemente de sua situação vacinal anterior. Naquele ano, ocorreu uma forte adesão por parte da população, porém, com o passar dos anos, a taxa de vacinação caiu (REVISTA DA VACINA, 2017).

Em Santa Catarina, um novo surto de sarampo ocorreu no final de 1996 e se alastrou por mais dezoito estados. A Campanha Nacional de Vacinação contra o Sarampo aconteceu em junho de 1997, atingindo uma cobertura vacinal acima de 95\%. A descontinuidade da transmissão da doença ocorreu em 2000, e foi possível por conta das ações de vigilância (REVISTA DA VACINA, 2017).

Os últimos casos de sarampo no Brasil foram registrados em 2015, assim o país recebeu a certificação de eliminação da circulação do vírus pela OMS, em 2016. Porém, no ano de 2018, foram registrados surtos em 11 Estados, o que provocou a perda do certificado e a continuidade da transmissão do vírus (BRASIL, 2019). 
De dezembro de 2019 a outubro de 2020, o Brasil registou 8.261 casos de sarampo em 21 estados. Apesar da rápida disseminação, os estados conseguiram conter a transmissão, exceto Pará, Rio de Janeiro, São Paulo e Amapá, onde o surto permaneceu ativo (FIOCRUZ, 2020).

\subsection{Rubéola}

No ano de 1992, se iniciou o controle da Rubéola com a criação da campanha de vacinação infantil em São Paulo, essa vacina foi implementada no calendário básico de imunização das crianças. Em 1997, foram notificados mais de 30.000 casos, desencadeando a necessidade de criar estratégias para prevenção e controle da rubéola e síndrome da rubéola congênita (REVISTA DA VACINA, 2017).

Mulheres em idade fértil participaram de campanhas de vacinação entre 1998 e 2002. Como ocorreu redução dos casos de síndrome da rubéola congênita, essas campanhas puderam ser consideradas efetivas. Após as campanhas de vacinação observou-se declínio significativo no número de casos de rubéola (REVISTA DA VACINA, 2017). 


\section{Capítulo6}

\section{MOVIMENTO ANTIVACINAS}

imunização vem ocupando espaço considerável entre os avanços na área da saúde, tornando evidente o desenvolvimento da imunologia, microbiologia, epidemiologia e sociologia, ressaltando o quanto a vacinação tem contribuído para promoção da saúde e prevenção de doenças (FEIJÓ E SÁFADI, 2006).

Em alguns países, onde a vacinação não é disponibilizada de forma gratuita, observa-se um movimento de redução na cobertura vacinal, fato este que está intimamente ligado a questões financeiras. Dessa maneira, as questões sociodemográficas, como falta de assistência aos serviços de saúde e a baixa renda familiar, ficam nítidas (LUIZ et al. 2021).

Segundo a OMS, várias são as causas que levam indivíduos a não se vacinarem e depende de pessoa para pessoa, alguns grupos se questionam a respeito da segurança das vacinas (TAB, 2021). Certos pais acreditam que o período entre uma vacina e outra é curto, principalmente no primeiro ano de vida.

Também são fortalecidas teorias nas quais pessoas afirmam que a vacinação é utilizada pelo governo como controle populacional, já outros afirmam que 
são contra a vacinação, devido a crenças religiosas ou hábitos de vida (VASCONCELOS E LARA, 2019).

Em 1998, o ex-pesquisador e ex-cirurgião britânico Andrew Wakefield, realizou um estudo e relacionou a vacina tríplice viral ao desenvolvimento do autismo, fato este que, posteriormente, foi confirmado ser fraude e que o pesquisador e médico tinha interesse em patentear uma nova vacina. No entanto, esse falso estudo se tornou uma grande ferramenta de fortalecimento do movimento antivacinas (TAB, 2021).

Outro fator que influencia na redução da cobertura vacinal e atinge os países desenvolvidos e em desenvolvimento, é o pensamento errôneo de que as doenças acabaram, fortalecendo a desinformação sobre as vacinas e, principalmente, o movimento antivacinas (LUIZ et al. 2021). Este movimento é fortalecido por uma considerável parcela da população que se baseia em notícias falsas através de plataformas digitais e apresenta uma propagação acelerada. Segundo dados do Ministério da Saúde, as fake News são o principal motivo da redução de indivíduos imunizados no país (SARAIVA E FARIA, 2019).

Durante as pesquisas, foi encontrado um grupo no Facebook denominado "Vacinas: o lado obscuro da vacina", que possui mais de 14 mil membros. Esse grupo conta com um acervo monstruoso de publicações, onde pessoas dizem que os vacinados não estão protegidos e que podem ainda desenvolver outras doenças como autismo, paralisia e até mesmo câncer (SARAIVA E FARIA, 2019).

Em uma entrevista para o portal de comunicação Universa da UOL (2017), o presidente do Departamento Científico de imunizações da Sociedade Brasileira de Pediatria (SBP), Renato Kfouri, informou que um dos possíveis motivos para a negligência dos pais de recém-nascidos em relação à vacinação é a falta de vivência da mortalidade causada pelas epidemias de antigamente (SBP, 2018).

Ao observar o número crescente de pessoas disseminando Fake News sobre vacinas, é fácil perceber uma possível volta de doenças erradicadas no Brasil, como varíola e poliomielite (LEVI, 2013). No Brasil, 
entre os anos 2015 a 2019, houve uma redução na taxa de vacinação. Sete das oito vacinas ofertadas para as crianças não atingiram a meta de imunização. Também houve uma queda na vacinação de adultos, registrouse a redução na procura e aplicação de quase todos os imunizantes disponíveis no Sistema Único de Saúde (BELTRÃO et al. 2020). 


\section{Capítulo7}

\section{PRINCIPAIS VACINAS PARA ADULTOS E SEUS IMPACTOS}

s vacinas estão entre as principais conquistas da humanidade e representam o investimento em saúde com melhor custo-benefício. São formuladas por meio agentes patogênicos (vírus ou bactérias, mortos ou atenuados) que estimulam a resposta imunológica do organismo, induzindo a produzir anticorpos, mesmo sem ter contraído a doença.

Um indivíduo, ao entrar em contato com o micro-organismo, terá uma resposta imunológica mais rápida e eficaz (VARELLA, 2013).

A imunização tem como objetivo proporcionar o não acometimento por doenças imunopreveníveis, sendo a estratégia de ação em saúde com maior impacto na diminuição da mortalidade e morbidade (Ministério da Saúde, 2003). Em 1973, foi criado o “Programa Nacional de Imunização” (PNI), com a missão de erradicar e controlar as doenças imunopreveníveis por meio do calendário básico de vacinação. O PNI coordena e define normas, procedimentos técnicos e científicos como conservação, armazenamento, transporte e manipulação das vacinas, rede de frios e administração de imunológicos (BRASIL, 2003).

De acordo com Moraes (2018), o Sistema Único de Saúde (SUS) fornece, gratuitamente, dezenove vacinas que beneficiam todas as faixas etárias. Conforme o Calendário Nacional de Vacinação de 2020, as principais vacinas para a população com idade entre 20 a 59 são as listadas a seguir: 


\subsection{Hepatite B}

A hepatite $B$ é um grande problema de saúde pública mundial. Estima-se que mais de 2 bilhões de pessoas possuem evidência sorológica de infecção presente ou passada pelo vírus da hepatite B (HBV 1 e 2), das quais 240 milhões mantêm-se como portadores de hepatite $B$ crônica, com possibilidades de desenvolver complicações como cirrose hepática ou hepatocarcinoma (SILVA, et al. 2017).

Historicamente, haviam registros de informações datadas há mais de cinco mil anos na literatura chinesa sobre as hepatites virais, fazendo referência à ocorrência de icterícia na população. Na Babilônia, surtos de icterícia foram registrados há mais de 2.500 anos. As grandes histórias de epidemias ou pandemias ictéricas geralmente estão associadas às grandes guerras (FONSECA, 2010).

Na guerra da Secessão Americana, houve 40 mil casos entre militares da União. Durante a Segunda Grande Guerra, mais especificamente em 1942, 28.585 soldados contraíram hepatite após a inoculação da vacina contra febre amarela. Durante o período do conflito citado, o número de casos de hepatite gira por volta de 16 milhões. Apenas no século XX foram identificados os principais agentes que causam as hepatites virais. $O$ vírus da hepatite $B$ foi o primeiro a ser descoberto (FONSECA, 2010).

Em 1981, nos Estados Unidos foi aprovada a primeira vacina contra o vírus da hepatite $B$, derivada de plasma de portadores crônicos do vírus. Surgiram então os imunizantes produzidos com material recombinante, dos quais os mais utilizados em nosso meio, são a Engerix B e a Recombivax. A descoberta de uma vacina eficaz e segura permitiu a implementação da imunização universal, adotada em mais de oitenta países, tornando-se uma medida essencial para a redução de infecção crônica pelo vírus $B$ da hepatite (HBV) (OSTI e MACHADO, 2010).

A hepatite do tipo $B$ é uma doença infecciosa transmitida pelo vírus HBV, que tem afinidade por infectar as células do fígado chamadas de hepatócitos. 0 vírus da hepatite $\mathrm{B}$ pode agredir essas células de forma direta ou por meio de células do sistema de defesa que, objetivando combater a infecção, acabam desenrolando um processo inflamatório crônico. Uma pessoa infectada por 
ele estará suscetível a desenvolver hepatite na forma aguda ou crônica (Dráuzio Varella).

As principais formas de transmissão são: relações sexuais com uma pessoa infectada sem o uso de preservativos, transmissão vertical de mãe para filho durante a gestação ou durante o parto, compartilhamento de material para uso de drogas, compartilhamento de materiais de higiene pessoal, confecção de tatuagem e introdução de piercings, procedimentos odontológicos ou cirúrgicos que não atendam às normas de biossegurança, por contato próximo de pessoa a pessoa e transfusão sanguínea (Ministério da Saúde, 2019). Os principais sinais e sintomas da hepatite B são: cansaço, tontura, enjoo e/ou vômitos, febre, icterícia e dor abdominal. Mas a infecção também pode se apresentar de forma assintomática (Secretaria da Saúde PR, 2019).

O diagnóstico é realizado através da pesquisa do antígeno viral (HBsAg), que pode ser realizado por meio de teste laboratorial ou teste rápido. Caso o resultado seja positivo, o diagnóstico deve ser confirmado com a realização de exames complementares para pesquisa de outros marcadores, que busca a detecção direta da carga viral, por meio de um teste de biologia molecular onde identifica a presença do DNA viral (HBV-DNA) (Ministério da Saúde, 2017). O tratamento da Hepatite $B$ é realizado com administração de antivirais específicos, disponibilizados pelo SUS, de acordo com o Protocolo Clínico e Diretrizes Terapêuticas vigentes (Ministério da Saúde, 2019).

A imunização realizada através vacina é a principal medida de prevenção contra a Hepatite $B$, geralmente, o esquema vacinal se dá com aplicação de três doses. O SUS disponibiliza a vacina nas unidades básicas de saúde para todas as pessoas. Além disso, existem outras formas complementares de prevenção como fazer o uso de preservativo em todas as relações sexuais, evitar compartilhar objetos de uso pessoal, como lâminas, escovas de dente, material de manicure e pedicure, seringas utilizadas para uso de drogas, confecção de tatuagem e introdução de piercings (Ministério da Saúde, 2017). 


\subsection{Febre amarela}

Transmitida por vetores artrópodes e causada primariamente por um vírus do gênero Flavivírus, da família Flaviviridae, a febre amarela é uma doença infecciosa febril aguda. (Ministério da Saúde, 2018). A doença foi o maior problema de saúde pública do país no século XIX até quase metade do século XX. Testemunhas relacionaram a eclosão da epidemia na capital do Império brasileiro à vinda de um navio negreiro oriundo de Nova Orleans, realizando escalas em Havana e Salvador antes de atracar no Rio de Janeiro em 3 de dezembro de 1849 (FIOCRUZ, 2008).

Em fevereiro de 1850, a febre amarela já havia se disseminado pelas praias dos Mineiros e do Peixe e Prainha. Segundo estimativas, atingiu 90.658 dos 266 mil habitantes do Rio de Janeiro, ocasionando 15 mil vítimas e 4.160 mortes, de acordo com os dados oficiais. Assim foi então constituída a Junta de Higiene Pública, que em 1886 transformou-se em Inspetoria Geral de Higiene e Inspetoria Geral de Saúde dos Portos (FIOCRUZ, 2008).

Segundo Thomas Monath, a produção da vacina de febre amarela foi instituída no Brasil entre janeiro e março de 1937, pelo Instituto de Tecnologia em Imunobiológicos Bio-Manguinhos. O imunizante era constituído por vírus vivos atenuados, derivados de uma amostra africana do vírus amarílico selvagem denominado Asibi. A produção brasileira da vacina 17DD de febre amarela ficou garantida no Instituto Oswaldo Cruz (FIOCRUZ, 2017).

Há duas formas de se contrair a febre amarela, a silvestre, transmitida de macacos infectados para os humanos através do mosquito Haemagogus, e a urbana, que ocorre quando o mosquito Aedes aegypti, transmite de um homem infectado para o outro suscetível (Biblioteca Virtual em Saúde, 2004).

Os sintomas clássicos caracterizam-se pelo surgimento súbito de febre alta, cefaleia intensa, inapetência, náuseas e mialgia. É facultativo o sinal de Faget (bradicardia acompanhando febre alta), ou seja, pode ou não se manifestar. Nas formas leves e moderadas, os sintomas duram cerca de dois a quatro dias. As formas graves e malignas acometem entre $15 \%$ a $60 \%$ das pessoas com sintomas que são notificados durante as epidemias, com evolução para óbito entre 20\% e 50\% dos casos (Ministério da Saúde, 2018). 
A confirmação laboratorial de febre amarela é realizada através dos testes histopatológico, sorológico e virológico, este último é confirmatório e considerado o "padrão ouro", podendo ser realizado pelas seguintes técnicas: isolamento do vírus da febre amarela e/ou detecção de antígenos virais e/ou ácido nucléico viral (Biblioteca Virtual em Saúde, 2004).

O tratamento costuma ser de acordo com os sinais e sintomas do paciente. Nas formas graves, o paciente deve ser atendido em uma Unidade de Terapia Intensiva, o que reduz a letalidade e possíveis complicações frequentemente encontradas em pacientes graves como disfunções hepática, renal, da coagulação e hemodinâmica, bem como os sintomas gerais mais exuberantes, como cefaleia, náuseas, vômitos e agitação (Biblioteca Virtual em Saúde, 2004).

Haja vista a forma da transmissão urbana da febre amarela, que é possível apenas através da picada de mosquitos Aedes aegypti, medidas de prevenção da doença devem ser adotadas com o intuito de evitar a propagação desses mosquitos, como: não deixar recipientes como caixas d'água, latas e pneus contendo água parada; fazer a aplicação de inseticida através do "fumacê"; fazer uso de repelentes, mosquiteiros e de roupas que cubram todo o corpo (FIOCRUZ, 2020).

A principal medida de prevenção contra a febre amarela é a vacina, que deve ser administrada em dose única $(0,5 \mathrm{ml})$ e com reforço a cada 10 anos, a vacina está disponível nas unidades básicas de saúde de forma gratuita (Biblioteca Virtual em Saúde, 2004). Segundo Souza et al. (2019), devido à deficiência na cobertura vacinal nas áreas de risco e a deficiência de informações para a população, têm ocorrido o aumento no número de casos da doença, descritos nos boletins epidemiológicos (SOUZA, 2019).

\subsection{Tríplice viral (SCR)}

\section{Sarampo}

A data exata do aparecimento desta doença é controversa, contudo, o genoma do vírus do sarampo foi sequenciado em 1912, sendo utilizada uma técnica molecular para determinar a data aproximada de surgimento do 
vírus. As análises mostram que o vírus do sarampo surgiu potencialmente já no século VI A.C., possivelmente coincidindo com o surgimento das grandes cidades (DUX et al. 2020).

O sarampo é uma doença infectocontagiosa causada por um vírus chamado Morbillivirus, que muitas vezes pode ser letal. No Brasil, graças às sucessivas campanhas de vacinação e programas de vigilância epidemiológica, a mortalidade não chegava a 0,5\% (Biblioteca Virtual em Saúde, 2007). A transmissão ocorre diretamente de uma pessoa para outra por meio de secreções expelidas pelo infectado ao tossir, falar ou espirrar, essas partículas serão inaladas por uma pessoa sadia, que se tornará infectada (Biblioteca Virtual em Saúde, 2007).

A fase de incubação do sarampo dura de 10-14 dias e geralmente é assintomática. Quando há manifestação de sinais e sintomas, estes podem ser: febre, mal-estar, tosse, coriza, conjuntivite, manchas brancas na parte interna das bochechas e manchas avermelhadas na pele que começa no rosto e progride em direção aos pés. Também pode apresentar complicações comuns como: pneumonia primária ou secundária, otite, ceratoconjuntivite e diarreia (XAVIER et al. 2019).

Os critérios que devem ser seguidos para o diagnóstico são: clínicos, laboratoriais e epidemiológicos. O diagnóstico laboratorial mais usado é o ensaio imunoenzimático (ELISA) para detecção de anticorpos específicos $\operatorname{lgM}$, que estão presentes de 3 dias até 4 semanas após o aparecimento dos sintomas. $\mathrm{O}$ vírus do sarampo também pode ser identificado pela técnica de RT-PCR, em amostras coletadas até o quinto dia a partir do aparecimento das manchas na pele, preferencialmente nos três primeiros dias, através de espécimes clínicos (sangue, urina e secreção nasofaringe) (CARVALHO et al. 2019).

O sarampo não possui um tratamento específico, geralmente é sintomatológico, ou seja, usam-se medicamentos como antitérmicos, reposição nutricional, higienização dos olhos, pele e trato respiratório superior para aliviar o desconforto causado pela doença, tendo em vista que as infecções bacterianas secundárias serão tratadas especificamente (Biblioteca Virtual em Saúde, 2019). 


\section{Caxumba}

A caxumba ou parotidite infecciosa é uma doença altamente contagiosa, causada pelo vírus RNA Paramyxovirus, transmitido por contato direto com perdigotos de pessoas infectadas (FIOCRUZ, 2018). Tem um período de incubação de duas ou três semanas. Seus primeiros sintomas são: febre, calafrios, dores de cabeça, dor ao mastigar ou engolir alimentos e fraqueza.

Uma das principais características da doença é o aumento das glândulas salivares próximas aos ouvidos que fazem o rosto inchar, em casos graves pode causar surdez, meningite e, raramente, levar à morte. Após a puberdade, pode causar inflamação e inchaço doloroso dos testículos ou dos ovários e levar à esterilidade (FIOCRUZ, 2018).

O diagnóstico da caxumba é basicamente clínico, realizado através da avaliação médica nas glândulas. Para confirmação laboratorial, o profissional de saúde pode coletar uma amostra de sangue para observar a presença do vírus ou anticorpos contra o Paramyxovirus (Ministério da Saúde, 2020).

O tratamento da caxumba é baseado nos sintomas clínicos do paciente, com adequação da hidratação e alimentação. Os pacientes devem evitar alimentos ácidos, pois podem ocasionar dor, náuseas e até vômitos. Além disso, a boa higiene bucal é fundamental. Por ser uma infecção viral, o próprio organismo consegue combater, entretanto, para aliviar sintomas, os analgésicos e antitérmicos podem ser utilizados (Ministério da Saúde, 2020).

\section{Rubéola}

A rubéola era conhecida na antiguidade pelos médicos árabes como uma variedade do sarampo. Em 1752 e 1758, respectivamente, os médicos alemães Bergen e Orlow foram os pioneiros ao realizarem a descrição da doença, classificada primariamente como "sarampo alemão". Uma pandemia da rubéola teve início na Europa entre 1962 e 1963 e nos Estados Unidos entre 1964 e 1965. Nos EUA ocorreram cerca de 12,5 milhões de casos e 11.000 mil óbitos fetais. Aproximadamente 20.000 mil recémnascidos nasceram com malformações compatíveis com a Síndrome da Rubéola Congênita (SRC) e 2.100 mil vieram a falecer no período neonatal (Secretaria De Estado De Saúde De São Paulo, 2007). 
A rubéola é uma doença aguda e contagiosa, causada pelo Rubivírus. A transmissão ocorre de pessoa para pessoa através da emissão de gotículas das secreções respiratórias dos doentes. É pouco frequente a transmissão através do contato com objetos recém-contaminados (FIOCRUZ, 2018). Nota-se a relevância epidemiológica da rubéola nos casos de Síndrome de Rubéola Congênita (SRC), que acomete o feto ou recém-nascido, cujas mães se infectaram durante o período gestacional. (Ministério da Saúde, 2019).

O período de incubação varia de duas a três semanas, após essa fase, a doença mostra seus primeiros sinais característicos: febre baixa, aumento dos gânglios linfáticos e manchas rosadas, que se espalham inicialmente no rosto e depois pelo resto do corpo, também podem ter dores de garganta e cabeça, e como esses dois últimos sintomas são frequentes em outras doenças, pode ocorrer um retardo no diagnóstico (FIOCRUZ, 2018).

Para o diagnóstico da rubéola, são realizados exames laboratoriais, disponíveis na rede pública em todos os estados, como titulação de anticorpos IgM e IgG para rubéola (Ministério da Saúde, 2019). Não existe tratamento específico para essa doença. Os sinais e sintomas apresentados devem ser tratados de acordo com a sintomatologia e terapêutica adequada, conforme cada caso (Ministério da Saúde, 2019).

A forma de prevenção contra sarampo, caxumba e rubéola é através da vacina tríplice viral, que oferece imunização ao indivíduo contra essas três doenças. A vacina foi registrada no início da década de 1970 e está sendo utilizada no Brasil desde 1992. As doses são administradas ainda na infância, mas nos casos de adultos que não tenham tomado à vacina na idade preconizada recebem duas doses até 29 anos, ou uma dose de 30 a 49 anos de idade (NETTO et al. 2010).

\subsection{Dtpa}

\section{Difteria}

A doença Difteria foi relatada no século $V$ a.C. por Hipócrates, e as epidemias foram descritas no século VI d.C. por Aécio. A bactéria foi analisada pela primeira vez em membranas diftéricas por Edwin Klebs em 1883 e cultivada por Friedrich Löffler em 1884 (CDC, 2020). 
A difteria é uma doença transmissível, causada pela bactéria Corynebacterium diphtheriae e sua transmissão ocorre através de gotículas expelidas durante a tosse, espirro ou fala de pessoas contaminadas e/ou de forma indireta através de objetos que estejam contaminados. Essa bactéria atinge principalmente as amígdalas, faringe, laringe, nariz e, ocasionalmente, outras partes do corpo, como pele e mucosas, podendo causar placas. Dependendo do tamanho e de onde as placas aparecerem, o indivíduo pode ter dificuldade de respirar (Ministério da Saúde, 2019). A incidência da transmissão de difteria costuma aumentar nos meses frios e principalmente, em ambientes fechados, devido à aglomeração (FIOCRUZ, 2018).

Após seis dias, normalmente começam a surgir os principais sintomas da condição, quais sejam: membrana grossa e acinzentada cobrindo as amígdalas e, inclusive, podendo cobrir outras estruturas da garganta, dor de garganta discreta, gânglios inchados (linfonodos aumentados) no pescoço, dificuldade em respirar ou respiração rápida em casos graves, palidez, febre não muito elevada e mal-estar geral (Ministério da Saúde, 2019).

O diagnóstico da difteria é clínico, baseando-se nos sintomas e características típicas da doença. Para confirmação do diagnóstico, o médico solicita a coleta de secreção da nasofaringe para cultura. Em casos de suspeita de difteria cutânea (na pele), devem ser coletadas amostras das lesões da pele (Ministério da Saúde, 2019). O tratamento da difteria é feito com o soro antidiftérico (SAD), que deve ser ministrado em unidade hospitalar, com a finalidade de inativar a toxina da bactéria o mais rapidamente possível. O uso do antibiótico é considerado como medida auxiliar do tratamento, ajudando a interromper o avanço da doença (Ministério da Saúde, 2019).

\section{Tétano}

O tétano já era conhecido há mais de 2000 anos. Hipócrates, em 640 a.C., já o descrevia em suas duas formas, generalizada e localizada, chegando o mesmo a ser o autor do aforismo: "tetânico que passar do quarto dia estará salvo". Hoje, apesar de todo progresso terapêutico, os óbitos ocorrem mais frequentemente nos quatros primeiros dias. Estima-se que há cerca de 50.000 casos de tétano por ano, em todo mundo e que essa incidência está relacionada à ausência de imunização contra a bactéria responsável pela doença (SILVA, 2010). 
O Tétano caracteriza-se por ser uma infecção aguda e grave, originária da toxina do bacilo tetânico (Clostridium tetani), que é introduzido no organismo através de ferimentos ou lesões na pele e não há contágio de uma pessoa para outra. 0 tétano é decorrente de acidentes e se manifesta pelo aumento da tensão muscular geral (FIOCRUZ, 2018). A contaminação se dá pela introdução dos esporos da bactéria em ferimentos externos, geralmente causados por objetos perfurantes e contaminados com terra, poeira, fezes de animais ou humanas. 0 bacilo é encontrado no intestino dos animais, principalmente do cavalo e do homem (não causando doença) e os esporos marcam presença tanto em solos contaminados por dejetos como fezes ou ou com esterco, como na pele ou na poeira das ruas (FIOCRUZ, 2018).

A toxina produzida pela bactéria ataca, principalmente, o sistema nervoso central e provoca: rigidez muscular em todo o corpo, mas principalmente no pescoço, dificuldade para abrir a boca e para engolir, riso convulsivo involuntário, produzidos por espasmos dos músculos da face. Essa contração muscular pode afetar os músculos respiratórios e levar o paciente a óbito (Bibloteca Virtual Em Saúde, 2020).

O diagnóstico do tétano prescinde de confirmação laboratorial, ou seja, é clínico. Os exames laboratoriais possuem a atribuição de apenas auxiliar no controle das complicações e tratamento do paciente. Excetuando-se os casos em que existem outas infecções, o hemograma habitualmente é normal. Devem ser realizadas radiografias de tórax e coluna vertebral para o diagnóstico de infecções pulmonares e fraturas de vértebras. Hemoculturas, culturas de secreções e de urina, são indicadas apenas nos casos de outra infecção (Ministério da Saúde, 2019). O tétano é uma doença grave e pode ser fatal, requer um tratamento o mais rápido possível onde são utilizados antibióticos, relaxantes musculares, sedativos, imunoglobulina antitetânica e, na falta dela, soro antitetânico (Biblioteca Virtual Em Saúde, 2020).

\section{Coqueluche}

Originária da bactéria Bordetella pertussis, a coqueluche é uma infecção respiratória transmissível e se faz presente no mundo todo. Sua característica marcante são as incontroláveis crises de tosse seca, sucedidas pelo guincho inspiratório, som produzido pelo encurtamento da glote. A doença pode atingir, também, traqueia e brônquios (Distrito Federal, 2020). 
A transmissão ocorre principalmente pelo contato direto da pessoa doente com uma pessoa não vacinada através de gotículas de saliva expelidas por tosse, espirro ou ao falar. Caso haja contato com objetos contaminados por secreções de um infectado, pode ocorrer a transmissão. A coqueluche é, especialmente, transmissível na fase catarral e em locais com aglomeração de pessoas (FIOCRUZ, 2018).

Os sintomas podem se manifestar em três níveis. No primeiro nível, o mais leve, os sintomas são parecidos com o de um resfriado, que são: mal-estar geral, corrimento nasal, tosse seca, febre baixa. Esses sintomas iniciais podem perdurar durante semanas, época que coincide com o período em que a pessoa está mais suscetível a transmitir a doença. No estágio intermediário, a tosse seca agrava-se e outros sinais surgem, como a mudança da tosse de leve para severa e descontrolada, podendo ser tão intensa que chega ao ponto de dificultar a respiração, provocando também, em alguns casos, vômitos e cansaço intenso. Nessa fase, os sintomas são mais severos e, dependendo do tratamento, podem durar até mais de um mês (Ministério da Saúde, 2019).

Seu diagnóstico em estágios iniciais é difícil, já que a doença possui similaridades sintomáticas com outras condições, como resfriado, por exemplo. A tosse seca é um forte indicativo da doença, mas para confirmar o diagnóstico, o médico pode pedir os seguintes exames: coleta de material de nasofaringe para cultura, PCR em tempo real e exames complementares, podem ser realizados hemograma e raio-x de tórax (Ministério da Saúde, 2019).

O tratamento é realizado com antibióticos prescritos por um médico especialista, conforme cada caso. É importante procurar uma unidade de saúde para receber o diagnóstico e tratamento adequado, assim que surgirem os primeiros sinais e sintomas (Ministério da Saúde, 2019). A prevenção à coqueluche é possível apenas depois do recebimento de três doses da vacina tríplice bacteriana ou DTP. Ela também está presente no calendário de vacinação de gestantes, com a vacina DTpa. No início da década de 1980, eram registrados no Brasil cerca de 36 mil casos anuais. Já em 2019, esse número reduziu para 1.495 doentes no país (Agência Brasília, 2020).

Segundo Clements e Griffiths (2002, p. 15) apud Prestes (2008, p.15), a vacina tríplice bacteriana clássica começou a ser administrada a partir dos anos 1920 em países mais desenvolvidos, focada primariamente nas classes mais 
abastadas da sociedade. Em 1974, foi criado o Programa Internacional de Imunização, que foi adotado por vários países garantindo a democratização do acesso à DTP e aumentando a cobertura de imunização contra esses antígenos.

Os profissionais da área da saúde devem receber uma dose e mais um reforço a cada 10 anos e as gestantes devem ser imunizadas a partir da vigésima semana gestacional, recebendo uma dose (Ministério da Saúde, 2020).

\subsection{Dupla adulto (dT)}

Em 1998, houve a substituição da vacina isolada contra tétano pela vacina Dupla adulto (dT), abrangendo a imunização em uma única vacina contra tétano e difteria (FIOCRUZ, 2019). A vacina dupla adulto é uma vacina inativa que oferece proteção contra Difteria e Tétano. Adolescentes que nunca tomaram a vacina podem tomar em qualquer idade e quem recebeu uma dose de dupla adulto aos dez ou onze anos necessita da dose reforço a cada década (Biblioteca Virtual em Saúde, 2003).

Além de preservar vidas, esses imunobiológicos possibilitaram um aumento de pelo menos 30 anos na expectativa de vida da humanidade, propiciando a redução de internações e superlotação do sistema de saúde e a diminuição do custo relacionado ao adoecimento por patologias imunopreveníveis. Para que esses resultados positivos se perpetuem, é necessário que haja um maior alcance e participação da população (LUZ et al. 2019).

Por isso é importante reforçar que, mesmo a vacinação sendo um sucesso na eliminação de várias patologias, ainda há necessidade de tomar às vacinas, caso contrário, as doenças antes controladas, podem voltar a ocorrer na população com grande risco de epidemia. Portanto, a vacinação é uma das medidas mais efetivas para a prevenção de doenças, oferecendo imunização individual e coletiva de uma população, e sendo responsável por erradicar doenças. A importância de se vacinar não está somente na proteção individual, mas também porque ela evita a propagação em massa de doenças que podem levar à morte ou a sequelas graves, comprometendo a qualidade de vida e saúde das pessoas vitimadas (FIOCRUZ, 2018). 


\section{Capítulo8}

\section{IMPORTÂNCIA DA VACINAÇÃO NA INFANCIA}

primeira vacina foi criada após o surgimento da varíola, uma doença que matou mais de 300 milhões de pessoas em todo território mundial. A varíola foi erradicada no mundo em 1796 e apenas em 1837 o Brasil declarou a obrigatoriedade da vacina contra a varíola para crianças.

Graças a essa primeira vacina e ao desenvolvimento científico no decorrer dos anos, houve a produção de diversas vacinas importantes que se tornaram obrigatórias, como a BCG, Hepatite A, Hepatite B e Tétano. A implementação dessas vacinas no calendário vacinal infantil promoveu o aumento da expectativa de vida e, atualmente, o Brasil tem um dos melhores programas de imunização do mundo, produzindo $96 \%$ das vacinas utilizadas. Certamente, o foco na prevenção foi um dos principais motivos para a redução da mortalidade infantil no país (FIOCRUZ, 2005).

A partir de 1940, foram observadas diminuições contínuas nas taxas de mortalidade das crianças até 5 anos de idade. A mortalidade infantil apresentou uma queda significativa de 91,9\% entre os anos de 1940 e 2019. Em 1940, a taxa de mortalidade na infância era de aproximadamente 212,1 óbitos para cada mil nascidos vivos e em 2019 foi de 14,0 por mil nascidos vivos. Em 1940, a expectativa de vida de uma pessoa era de 69,1 anos. Já em 2019 a expectativa de vida de uma pessoa era 80,8 anos. A expectativa de vida teve um aumento de 11,8 anos durante esse período. Portanto, com a melhora dos serviços de saúde ao decorrer do tempo se verificou a 
diminuição significativa da mortalidade infantil e o aumento na expectativa de vida (IBGE, 2019).

A vacinação infantil é de extrema importância, pois ela atua na proteção e prevenção de doenças que são imunopreveníveis, além de evitar possíveis ocorrências de surtos epidêmicos. As vacinas são fabricadas a partir de vírus ou bactérias inativadas, e até mesmo microrganismos inteiros vivos atenuados (enfraquecidos). Quando a vacina é introduzida no organismo de uma pessoa, ela estimula o sistema imune do indivíduo a desenvolver anticorpos, que irão produzir uma defesa contra os microrganismos que provocariam a doença. Estes anticorpos ativam células de memória do sistema imunológico, de forma a evitar que o indivíduo desenvolva a doença ao ser exposto a ela, obtendo assim a imunidade (SOUSA, 2012).

A imunização é uma das estratégias de saúde mais importantes para a prevenção da mortalidade infantil. No ano de 2001, foram registrados 61.000 mil óbitos infantis e a cobertura vacinal foi de $79,85 \%$. Com o passar das décadas, nota-se uma diminuição no número de óbitos infantis, passando para 35.293 casos, enquanto a cobertura vacinal foi reduzida para $66,52 \%$, em todo o Brasil (DATASUS, 2021).

Foram estabelecidos, pelo Ministério da Saúde, calendários vacinais específicos, de acordo com a faixa etária infantil. Os pais devem estar atentos para que possam vacinar seus filhos no tempo certo, pois, caso haja atraso ou até mesmo não seja administrado alguma vacina, a criança pode correr o risco de se infectar com alguma doença grave que poderia ter sido evitada com a vacinação. Dentre essas vacinas podemos citar as principais:

\subsection{BCG}

A vacina BCG foi produzida em 1921 por Léon Calmette e Alphonse Guérin. Sua ação é proteger contra a tuberculose, doença contagiosa provocada por uma bactéria que afeta os ossos, rins, meninges e principalmente os pulmões. É ofertada pelo SUS e deve ser aplicada ao nascer, ou no máximo até os 4 anos de idade (BIBLIOTECA VIRTUAL EM SAÚDE, 2020). 
Os principais sintomas da tuberculose ativa no pulmão são: tosse, às vezes com expectoração e sangue, falta de ar, dores no peito, fraqueza, perda de peso e febre frequentes, principalmente ao final do dia (BIBLIOTECA VIRTUAL EM SAÚDE, 2020). A cobertura vacinal acumulada da vacina BCG em 2014 era de 107,28\%, contabilizando 13 óbitos decorrentes da tuberculose. Em 2019, foram registrados 11 óbitos e a cobertura vacinal foi para $86,67 \%$ (DATASUS, 2021).

\subsection{POLIOMELITE}

A imunização contra a poliomielite previne contra a paralisia infantil e ocorrem de duas formas: Vacina Inativada da Poliomielite (VIP) é administrada aos 2, 4 e 6 meses de vida e a Vacina Oral da Poliomielite (VOP) é administrada aos 15 meses e tem reforço aos 4 anos. A poliomielite é uma doença causada por um vírus que vive no intestino, o poliovírus. Ocorre com maior frequência em menores de 4 anos, mas pode acometer também adultos. Aproximadamente $1 \%$ das pessoas que são acometidas pelo vírus pode desenvolver a forma paralítica da doença, podendo levar à sequelas permanentes, insuficiência respiratória ou até mesmo à morte. Quando a paralisia se manifesta, acomete os membros inferiores, podendo atingir apenas um dos membros (SECRETARIA DE SAÚDE DO DISTRITO FEDERAL, 2021).

Sua transmissão pode ocorrer de pessoa para pessoa por via fecal-oral, contaminação de água e alimentos, gotículas de espirro e tosse. Não acontece no Brasil desde o ano de 1989. A cobertura vacinal contra a doença foi de $96,76 \%$ em 2014, declinando para 75,82\% em 2020 (DATASUS, 2021).

Em 1994, o Brasil recebeu da Organização Pan-americana da Saúde (OPAS) a Certificação de área livre de circulação do poliovírus selvagem em seu território, juntamente com os demais países das Américas. O país, desde então, vem realizando esforços para atingir a meta dos indicadores preconizados pelo Ministério da Saúde para manutenção do país livre da doença (GDF, 2021). 


\subsection{HEPATITE B}

A hepatite $B$ é uma infecção grave do fígado que não tem cura. É transmitida com maior frequência pela exposição a fluidos corporais, mas também pode ser de mãe para filho durante a gestação ou o parto. Na maioria dos casos, em fase inicial, não há a presença de sintomas, dificultando o diagnóstico precoce da infecção. Para se detectar a presença do vírus, é realizado um teste rápido baseado na técnica de imunocromatografia de fluxo lateral, que permite a deteç̧ão do antígeno de superfície do HBV (HBsAg) no soro, plasma ou sangue total, que pode ser feito na Unidade Básica de Saúde. (SECRETARIA DA SAÚDE DO PARANÁ, 2021).

A principal forma de prevenção é a vacina, disponibilizada pelo SUS, independentemente da idade. Para crianças, a recomendação é a administração de quatro doses da vacina, isto é, ao nascer, aos 2, 4 e 6 meses de idade. Após dois meses do término do esquema de vacinação pode ser realizada a sorologia para detecção do anti-HBs, confirmando o sucesso da vacina. (MD. SAÚDE, 2021).

Após 10 anos de uso da vacina, alguns países registraram a redução na prevalência de marcadores de HBV (HBsAg e anti-HBc) na população menor de 12 anos de idade, passando respectivamente de $9,8 \%$ para $1,3 \%$ e de $26 \%$ para 4\%. O vírus da Hepatite B está relacionado a $21,3 \%$ das mortes relacionadas a Hepatites entre 2000 e 2017. A cobertura vacinal preventiva contra a Hepatite B foi de 96,42\% em 2014, diminuindo para 76,88\% em 2020 (DATASUS, 2021).

\subsection{PNEUMOCÓCICA VALENTE 10}

O pneumococo tem se apresentando como principal causador de infecções em neonatos e em crianças até 2 anos de idade, sendo responsável por 45\% das pneumonias adquiridas na comunidade, além de otites, sinusites, meningites e bacteremias na infância. Nos países em desenvolvimento, a bactéria corresponde $27 \%$ dos casos de pneumonia em crianças e por $70 \%$ dos casos de doenças invasivas em menores de 2 anos de idade. A estimativa 
é de que, nos países mais pobres, por volta de 5 milhões de crianças abaixo de 5 anos de idade, sucumbem anualmente à pneumonia. Destas 1 milhão são acometidas pelo pneumococo (SCG Goiás, 2010).

A vacina pneumocócica valente 10 aprovada no Brasil em 2009 previne cerca de $70 \%$ das doenças graves em crianças (pneumonia, meningite e otite), causadas por dez sorotipos de pneumococo, as doses da vacina devem ser aplicadas aos 2, 4 e 12 meses de vida. Segundo a Sociedade Brasileira de Imunizações ocorreu uma redução de até $40 \%$ no número de internações por pneumonia e de $70 \%$ dos casos de meningite pneumocócica (FIOCRUZ, 2019). A cobertura vacinal preventiva em 2014 era de 93,45\% contabilizando 1.668 óbitos decorrentes dos sorotipos de pneumococos, em 2019, a cobertura vacinal foi para $89,07 \%$ (DATASUS, 2021).

\subsection{PENTAVAlENTE}

A vacina pentavalente protege contra a difteria, tétano, hepatite $B$, coqueluche e também contra a bactéria Haempophilus influenzae tipo $B$, causadora de infecções no nariz, garganta e meninge. A pentavalente é uma vacina que reúne em si 5 vacinas individuais simultaneamente, objetivando a proteção contra múltiplas doenças. Crianças devem tomar 3 doses das vacinas aos 3, 4 e 6 meses de vida (Ministério da Saúde, 2020).

No ano de 2014 a cobertura vacinal era de $94,85 \%$ com registro de 132 óbitos, já em 2019 foram registrados 9 óbitos. Em 2020 ocorreu a diminuição da cobertura vacinal para $76,88 \%$. Houve um desabastecimento dessa vacina pela suspensão parcial desde julho de 2019 , justificada pela reprovação no teste de qualidade do instituto nacional de controle de qualidade em saúde e análise da agência nacional de vigilância sanitária (DATASUS, 2021). 


\subsection{ROTAVÍRUS}

O rotavírus é um vírus que causa diarreia grave constantemente acompanhada de vômito e febre alta. É um dos mais importantes agentes causadores de óbitos em crianças menores de 5 anos, caso a infecção não seja tratada adequadamente. Indivíduos de todas as idades são suscetíveis à infecção, porém ela é mais comum em crianças nos seus primeiros anos de vida. A transmissão ocorre por contato fecal-oral, água ou alimentos contaminados, contato pessoa para pessoa, objetos contaminados e secreções respiratórias (Ministério da Saúde, 2020).

No mundo cerca de 125 milhões de episódios diarreicos por rotavírus ocorrem a cada ano, causando entre 600.000 a 870.000 óbitos. Estima-se que no Brasil a taxa média de diarreia em crianças menores de três anos de idade seja de 2,5 episódios por criança/ano, das quais $10 \%(0,25)$ se associam aos rotavírus (Secretaria De Estado Da Saúde De São Paulo, 2006). No Brasil a cobertura vacinal em 2014 era de 93,44\% registrando-se 457 óbitos, enquanto em 2019 a cobertura vacinal declinou para $85,40 \%$ (DATASUS, 2021).

A vacina contra o rotavírus atua para proteção de gastroenterites. São aplicadas duas doses por via oral; a primeira dose é aplicada aos 2 meses de vida e a segunda dose com 4 meses. A vacina contra o rotavírus não deve ser administrada em crianças com história de doença gastrointestinal crônica, má formação congênita do trato gastrointestinal e em crianças com imunodeficiências primárias e secundárias (SÍRIO-LIBANÊS 2021).

\subsection{MENINGOCOCOC}

As doenças causadas pelas bactérias meningocócicas são de evolução muito rápida e em algumas situações podem ser graves e letais. A vacina meningocócica $C$ ajuda na proteção contra a meningite que é uma inflamação nas meninges. Aproximadamente 500.000 casos de doença meningocócica invasiva ocorrem todo ano no mundo, deixando cerca de 60.000 pacientes com sequelas permanentes e resultando em mais de 50.000 mortes (SÁFADI, 2006). 
Essa doença apresenta sua maior incidência em crianças menores de 5 anos de idade, especialmente lactantes de 3 e 12 meses. O Brasil registrou, na década de 1970, a maior epidemia de doença meningocócica do país, com o epicentro em São Paulo e é caracterizada pela sobreposição de duas ondas epidêmicas, a primeira provocada pelo meningococo $C$, com início em abril de 1971, e a segunda pelo meningococo A, iniciada em abril de 1974, sem que a incidência de casos relacionados ao meningococo $C$ tivesse retornado aos valores endêmicos. A taxa de incidência que era de 2,1 casos por 100 mil habitantes em 1970 chegou à atingir a marca de 179 casos por 100.000 habitantes (SÁFADI, 2006).

A vacina meningocócica possui uma grande efetividade e deve ser tomada aos 3 e 5 meses com uma dose reforço aos 15 meses. Os países onde foram introduzidos programas de imunização em massa obteve uma drástica redução da incidência de doença meningocócica causada pelo sorogrupo C. No Brasil sua cobertura vacinal foi de $96,36 \%$ e 160 óbitos registrados em 2014. Em 2019, houve um declínio na cobertura vacinal para $87,41 \%$ (DATASUS, 2021).

\subsection{TRIPLICE VIRAL}

A vacina tríplice viral protege contra caxumba, rubéola e sarampo. Ela deve ser aplicada preferencialmente aos 12 meses de vida, para que haja redução de uma possível interferência na resposta ao estímulo vacinal do sarampo por anticorpos maternos adquiridos durante a gestação; a segunda dose deve ser administrada entre 4 e 6 anos de idade. A cobertura vacinal em 2014 do tríplice viral era de 112,80\% e em 2020 teve uma diminuição para 79,43\% (DATASUS, 2021).

O último caso confirmado de rubéola no Brasil ocorreu no mês de dezembro de 2008 no estado de São Paulo. No dia 23 de abril de 2015 o Brasil recebeu do Comitê Internacional de Experts um documento de verificação da eliminação da Rubéola e em 27 de setembro de 2016 recebeu um documento de eliminação do Sarampo, mas perdeu a certificação em 2019 devido à ocorrência de surtos pelo país (BRASIL, 2020). 


\subsection{FEBRE AMARELA}

A vacina da febre amarela está incluída no calendário de vacinação e pode ser administrada a partir do nono mês de vida da criança e desde 2020 começou a ser ofertada aos quatro anos de idade uma dose de reforço da vacina (Biblioteca Virtual Em Saúde, 2019). Sua cobertura vacinal em 2014 era de 46,86\%, já em 2020 teve um aumento para 54,06\% (DATASUS, 2021).

A vacina protege contra a febre amarela e suas complicações. Geralmente quem é contaminado pela doença não apresenta sintomas ou pode apresentar sintomas leves. Suas primeiras manifestações são: calafrios, febre alta, cansaço, dores de cabeça, dores musculares, náuseas e vômitos por três dias; e suas manifestações são repentinas. A forma grave da doença é rara e aparece após um período de bem-estar, podendo ocorrer insuficiência hepática e renal, olhos e pele amarelados, cansaço intenso e manifestações hemorrágicas (FIOCRUZ, 2020). Durante o monitoramento entre 2019 e 2020 foram notificados, em humanos, 749 casos suspeitos de febre amarela, dentre esses 100 permaneceram em investigação (Ministério da Saúde, 2020).

\subsection{DTP}

A difteria é uma doença infecciosa bacteriana que infecta as vias aéreas superiores e a garganta, produzindo toxinas que podem prejudicar a respiração, em seu estado grave pode ocasionar insuficiência cardíaca e danos neurais. O tétano é uma infecção grave, na qual bactérias liberam toxinas que prejudicam os tecidos do sistema nervoso, podendo causar contração muscular e espasmos. A coqueluche é uma infecção contagiosa dos pulmões e vias aéreas; cerca de $6 \%$ das crianças com a doença apresentam quadro de pneumonia e até $1 \%$ dos bebês de até um ano podem morrer como resultado da infecção (Ministério da Saúde, 2019). 
Figura 1: Tabela de vacinação infantil

\begin{tabular}{|c|c|c|c|c|c|c|c|c|c|c|c|c|c|c|c|c|c|c|}
\hline \multicolumn{19}{|c|}{ CALENDARIO NACIONAL DE VACINAÇĀO/2020/PNI/MS } \\
\hline \multicolumn{2}{|c|}{ varain } & вटक & Herente 11 & \begin{tabular}{|l|} 
vosy \\
Sotainatian
\end{tabular} & 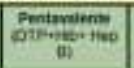 & जाए & SP a vis & \begin{tabular}{|c|} 
Pnemmexicea \\
so
\end{tabular} & Mentupockocia & Fenes: & Triplan knal & $\begin{array}{l}\text { Tolne } \\
\text { vina }\end{array}$ & 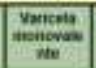 & inoution & HPV & 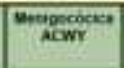 & Geppe & 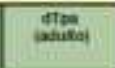 \\
\hline \multicolumn{2}{|c|}{ Preteve conts: } & \multirow{2}{*}{$\begin{array}{l}\text { Forvas } \\
\text { gares as } \\
\text { tuteratose }\end{array}$} & \multirow{2}{*}{ Heativ s } & \multirow{2}{*}{ Firaibs } & \multirow{2}{*}{ 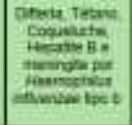 } & \multirow{2}{*}{ 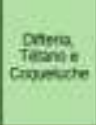 } & \multirow{2}{*}{ Pnkinnen } & \multirow{2}{*}{ 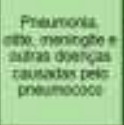 } & \multirow{2}{*}{ 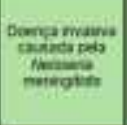 } & \multirow{2}{*}{$\begin{array}{l}\text { Foen } \\
\text { Aranti. }\end{array}$} & \multirow{2}{*}{ 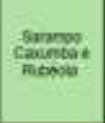 } & \multirow{2}{*}{ 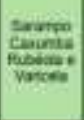 } & \multirow{2}{*}{ vetice } & \multirow{2}{*}{ Heighe } & \multirow{2}{*}{ HPV } & \multirow{2}{*}{ 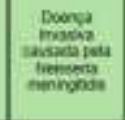 } & \multirow{2}{*}{$\begin{array}{l}\text { Denas } \\
\text { thase }\end{array}$} & \multirow{2}{*}{ onve rent } \\
\hline Grape NWe & itule & & & & & & & & & & & & & & & & & \\
\hline \multirow{11}{*}{ Criansa } & Nenascer & $\begin{array}{c}\text { Den unea } \\
\text { in }\end{array}$ & 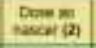 & & & & & & & & & & & & & & & \\
\hline & 2 neses & & & "osse & rane & & $\begin{array}{c}r=\operatorname{mag}^{\prime} \mathrm{VF} \\
\text { iII }\end{array}$ & rone & & & & & & & & & & \\
\hline & Snese & & & & & & & & ronese & & & & & & & & & \\
\hline & 4 mones & & & Pese & Fooiu & & $\begin{array}{c}z \text { woee } \\
\text { (i) }\end{array}$ & rese & & & & & & & & & & \\
\hline & sman & & & & & & & & $x$ ain & & & & & & & & & \\
\hline & sireses & & & & ranse & & $\frac{x \cos }{(1)} v$ & & & & & & & & & & & \\
\hline & smeses & & & & & & & & & Daseinas & & & & & & & & \\
\hline & 12 nosen & & & & & & & Fotow (9) & IV Restrote & & vane & & & & & & & \\
\hline & 15 manes & & & & & Fature & $\begin{array}{l}\text { renters } \\
\text { volsens }\end{array}$ & & & & & \begin{tabular}{|l|} 
Oode \\
Unarin
\end{tabular} & & Don & & & & \\
\hline & tane & & & & & F Aunvega: & 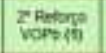 & & & Anotepeso & & & Fane 101 & & & & & \\
\hline & vanes & & & & & & & & & $\begin{array}{c}\text { Ureopose } \\
\text { (1) }\end{array}$ & & & & & $\begin{array}{c}2 \text { dosen } \\
\text { का }\end{array}$ & & & \\
\hline Audienrecte & 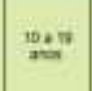 & & 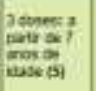 & & & & & & & unagues & $2 \mathrm{sem} 191$ & & & & 2.sonet & 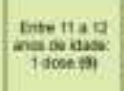 & 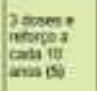 & 50 atr mor \\
\hline Nitaltm & now & & Janen as & & & & & & & $\begin{array}{c}\text { una poue } \\
\text { so }\end{array}$ & 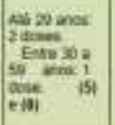 & & & & & & 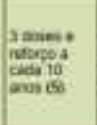 & 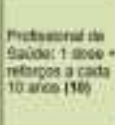 \\
\hline Haten & $\cos _{\operatorname{mat}}$ & & 3 dowet is & & & & & & & & & & & & & & 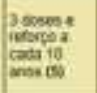 & \\
\hline \multicolumn{2}{|c|}{ Gestarits } & & $3000 \mathrm{~s}$. & & & & & & & & & & & & & & 2 accet is & 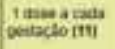 \\
\hline \multicolumn{19}{|c|}{ 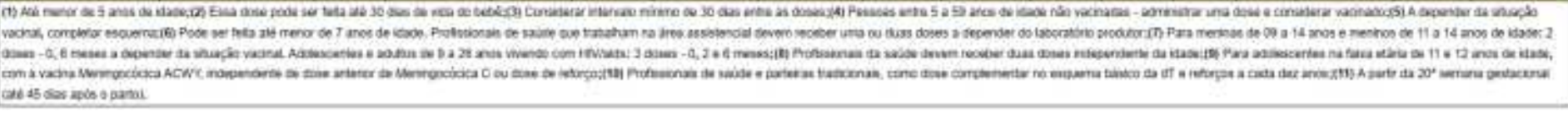 } \\
\hline
\end{tabular}

Fonte: Conasems, 2020.

A DTP é a única vacina que consegue proteger a mãe e o bebê dessas três doenças graves: a difteria, tétano e coqueluche. Sua cobertura vacinal em 2014 era de 95,48\%, e entre os anos de 2017 a 2020 não houve registro de dados (DATASUS, 2021). A gestante deve tomá-la em sua $20^{\circ}$ semana de gestação e a criança deve tomar 2 doses de reforço em seu $15^{\circ}$ mês e aos 4 anos de idade (Ministério da Saúde, 2019). 


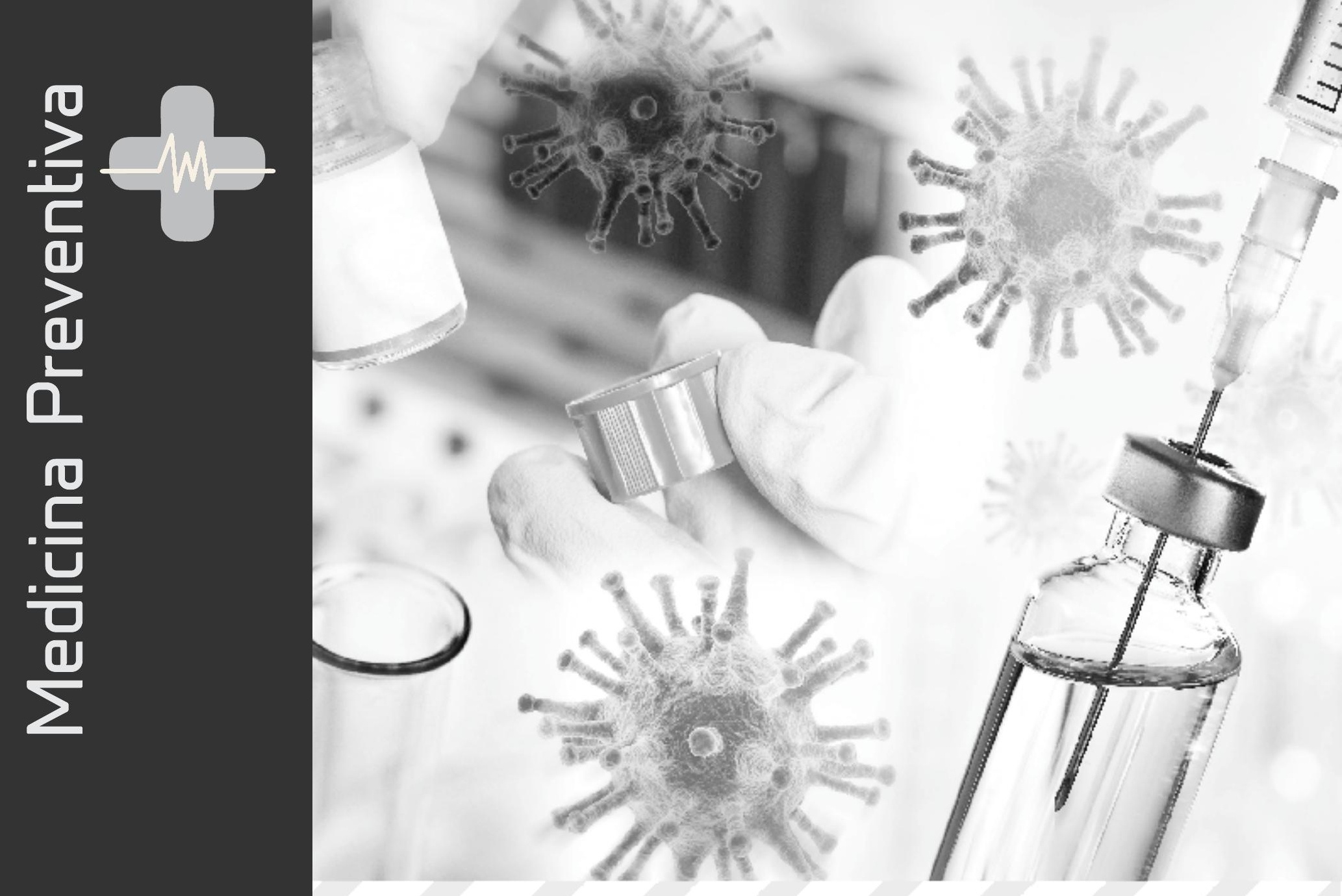




\section{REFERÊNCIAS BIBLIOGRÁFICAS}

AGÊNCIA BRASÍLIA. VACINA É A PRINCIPAL ARMA CONTRA COQUELUCHE. DISPONÍVEL EM: HTTPS://WWW.AGENCIABRASILIA.DF.GOV.BR/ 2020/09/07/VACINA-E-A-PRINCIPAL-ARMA-CONTRAACOQUELUCHE/ \#: :TEXT=A\%20PREVEN\%C3\%A7\%C3\%A30\%20\%C3\%A9\%20FEITA\%20COM,VA CINA\%C3\%A7\%C3\%A30\%20DO\%20MINIST\%C3\%A9RIO\%20DA\%20SA\%C3\%B ADE. ACESSO EM: 21 MAR. 2021.

ARQUISP. A PRAGA DE JUSTINIANO E SÃO GREGÓRIO MAGNO. DISPONÍVEL EM: HTTP://ARQUISP.ORG.BR/NOTICIAS/A-PRAGA-DE-JUSTINIANO-E-SAOGREGORIO-MAGNO. ACESSO EM: 15 MAR. 2021.

ATLAS HISTÓRICO DO BRASIL. GRIPE ESPANHOLA. DISPONÍVEL EM: HTTPS://ATLAS.FGV.BR/VERBETES/GRIPE-ESPANHOLA. ACESSOEM:12 MAR. 2021.

BELTRÃO, R. P. L. ET AL. PERIGO DO MOVIMENTO ANTIVACINA: ANÁLISE EPIDEMIO-LITERÁRIA DO MOVIMENTO ANTIVACINAÇÃO NO BRASIL. REVISTA ELETRÔNICA ACERVO SAÚDE. CAMPINAS, V. 12, P. 1-8, DEZ./2005. DOI: HTTPS://DOI.ORG/10.25248/REAS.E3088.2020. DISPONÍVEL EM: HTTPS://ACERVOMAIS.COM.BR/INDEX.PHP/SAUDE/ARTICLE/VIEW/3088. ACESSO EM: 12 MAR. 2021.

BIBLIOTECA VIRTUAL EM SAÚDE. 01/7 DIA DA VACINA BCG. DISPONÍVEL EM: HTTP://BVSMS.SAUDE.GOV.BR/ULTIMAS-NOTICIAS/3222-01-7-DIA-DAVACINA-BCG-2. ACESSO EM:15 MAR. 2021.

BIBLIOTECA VIRTUAL EM SAÚDE. DEZEMBRO VERMELHO: CAMPANHA NACIONAL DE PREVENÇÃO AO HIV/AIDS E OUTRAS INFECÇÕES SEXUALMENTE TRANSMISSÍVEIS. DISPONÍVEL EM: HTTP://BVSMS.SAUDE.GOV.BR/ULTIMASNOTICIAS/3368-DEZEMBRO-VERMELHO-CAMPANHA-NACIONAL-DEPREVENCAO-AO-HIV-AIDS-E-OUTRAS-INFECCOES-SEXUALMENTETRANSMISSIVEIS. ACESSO EM: 15 MAR. 2021.

BIBLIOTECA VIRTUAL EM SAÚDE. EM 2020, MINISTÉRIO DA SAÚDE AMPLIA PÚBLICO PARA VACINAS CONTRA FEBRE AMARELA E GRIPE. DISPONÍVEL EM: HTTP://BVS.SAUDE.GOV.BR/COMPONENT/CONTENT/ARTICLE?ID=3089. ACESSO EM 15 ABR. 2021. 
BIBLIOTECA VIRTUAL EM SAÚDE. SARAMPO. DISPONÍVEL EM: HTTP://BVSMS.SAUDE.GOV.BR/DICASEMSAUDE/2114SARAMPO\#: :TEXT=O\% 20SARAMPO\%20\%C3\%A9\%20UMA\%20DOEN\%C3\%A7A,CHEGA\%20A\%200\%2 C5\%25. ACESSO EM: 20 MAR. 2021.

BIBLIOTECA VIRTUAL EM SAÚdE. TÉTANO. DISPONÍVEL EM: HTTPS://BVSMS.SAUDE.GOV.BR/DICAS-EM-SAUDE/3141-TETANO. ACESSO EM: 21 MAR. 2021.

BIO-MANGUINHOS/FIOCRUZ. CONHEÇA A HISTÓRIA DAS VACINAS. DISPONÍVEL EM HTTPS://WWW.BIO.FIOCRUZ.BR/INDEX.PHP/BR/NOTICIAS/1738CONHECA-A-HISTORIA-DAS-VACINAS. ACESSO EM 12 MAR. 2021.

BJHR. MOVIMENTO ANTIVACINA: A PROPAGAÇÃO DE UMA DISTOPIA QUE AMEAÇA A SAÚDE DA POPULAÇÃO BRASILEIRA. DISPONÍVEL EM: HTTPS://WWW.BRAZILIANJOURNALS.COM/INDEX.PHP/BJHR/ARTICLE/VIEW/ 22731 \#: : TEX T = ( $\left.\begin{array}{llll}2 & 0 & 2 & 1\end{array}\right) \% 20 \% 3$ E \% 20 L U I Z ,MOVIMENTO\%20ANTIVACINA\%3A\%20A\%20PROPAGA\%C3\%A7\%C3\%A30\%2 ODE\%20UMA\%20DISTOPIA\%20QUE\%20AMEA\%C3\%A7A\%20A,HEALTH\%200F \%20THE\%20BRAZILIAN\%2OPOPULATION. ACESSO EM: 14 MAR. 2021.

BRASIL. A CADERNETA DA CRIANÇA: PASSAPORTE DA CIDADANIA. 5. ED. BRASÍLIA - DF: MS, 2008. P. 1-84.

BRASIL. A IMPORTÂNCIA DA VACINA DTPA PARA A MÃE E O BEBÊ. DISPONÍVEL EM: HTTP://WWW.BLOG.SAUDE.GOV.BR/INDEX.PHP/PROMOCAO-DASAUDE/53804-A-IMPORTANCIA-DA-VACINA-DTPA-PARA-A-MAE-E-O-BEBE. ACESSO EM:20 MAR. 2021.

BRASIL. CALENDÁRIO NACIONAL DE VACINAÇÃO/2020/PNI/MS. DISPONÍVEL EM: HTTPS://WWW.SAUDE.GO.GOV.BR/FILES/IMUNIZACAO/CALENDARIO/ CALENDARIO.NACIONAL.VACINACAO.2020.ATUALIZADO.PDF. ACESSO EM: 12 MAR. 2021.

BRASIL. CARTILHA DE VACINAS. DISPONÍVEL EM: HTTPS://BVSMS. SAUDE.GOV.BR/BVS/PUBLICACOES/CART_VAC.PDF. ACESSO EM:14 ABR. 2021.

BRASIL. CAXUMBA: O QUE É, CAUSAS, SINTOMAS, TRATAMENTO E PREVENÇÃO. DISPONÍVEL EM: HTTPS://ANTIGO.SAUDE.GOV.BR/SAUDE-DE-A-Z/CAXUMBA. ACESSO EM: 18 MAR. 2021.

BRASIL. COQUELUCHE: CAUSAS, SINTOMAS, DIAGNÓSTICO E PREVENÇÃO. DISPONÍVEL EM: HTTPS://ANTIGO.SAUDE.GOV.BR/SAUDE-DE-AZ/COQUELUCHE. ACESSO EM: 21 MAR. 2021. 
BRASIL. DIFTERIA: O QUE É, CAUSAS, SINTOMAS E PREVENÇÃO. DISPONÍVEL EM: HTTPS://ANTIGO.SAUDE.GOV.BR/ASSESSORIA-DE-IMPRENSA. ACESSO EM: 21 MAR. 2021.

BRASIL. DOENÇAS DE CONDIÇÕES CRÔNICAS E INFECÇÕES SEXUALMENTE TRANSMISSÍVEIS. HEPATITE B. DISPONÍVEL EM:HTTP://WWW.AIDS.GOV.BR/ PT-BR/PUBLICO-GERAL/HV/O-QUE-SAO-HEPATITES/HEPATITE-B\#. ACESSO EM: 21 MAR. 2021.

BRASIL. FEBRE AMARELA. DISPONÍVEL EM: HTTPS://PORTALARQUIVOS2. SAUDE.GOV.BR/IMAGES/PDF/2018/JANEIRO/18/GUIA-FEBRE-AMARELA2018.PDF. ACESSO EM: 21 MAR. 2021.

BRASIL. HEPATITE B: O QUE É, CAUSAS, SINTOMAS, TRATAMENTO, PREVENÇÃO. DISPONÍVEL EM: HTTPS://ANTIGO.SAUDE.GOV.BR/SAUDE-DE-A-Z/HEPATITE-B. ACESSO EM: 21 MAR. 2021.

BRASIL. INFORME TÉCNICO DA VACINA PNEUMOCÓCICA 10-VALENTE (CONJUGADA). DISPONÍVEL EM: HTTP://WWW.SGC.GOIAS.GOV.BR/ UPLOAD/LINKS/ARQ_723_INFOTEC.PDF. ACESSO EM: 20 MAR. 2021.

BRASIL. MANUAL DE VIGILÂNCIA EPIDEMIOLÓGICA DE FEBRE AMARELA. D I S P O I V E L E M : H T T P S : / / B V S M S. S A U D . G O V . B R / BVS/PUBLICACOES/MANUAL_VIGILANCIA_EPID_FEBRE_AMARELA.PDF. ACESSO EM: 21 MAR. 2021.

BRASIL. MONITORAMENTO DOS CASOS DE ARBOVIROSES URBANAS TRANSMITIDAS PELO AEDES AEGYPTI (DENGUE,CHIKUNGUNYA E ZIKA), SEMANAS EPIDEMIOLÓGICAS 1 A 15, 2020. DISPONÍVEL EM: HTTPS://WWW.GOV.BR/SAUDE/PT-BR/CENTRAIS-DE-CONTEUDO/BOLETIMEPIDEMIOLOGICO-SVS-16-PDF. ACESSO EM:20 MAR. 2021.

BRASIL. PENTAVALENTE. DISPONÍVEL EM: HTTPS://WWW.GOV.BR/SAUDE/PTBR/ASSUNTOS/SAUDE-DE-A-A-Z-1/P/PENTAVALENTE. ACESSOEM:20 MAR. 2021.

BRASIL. PROGRAMA NACIONAL DE IMUNIZAÇÕES. PNI 30 ANOS. BRASÍLIA. D I S P O NÍ V E L E M : H T T P S : / / B V SM S. S A U D . G O V . B R / BVS/PUBLICACOES/LIVRO_30_ANOS_PNI.PDF ACESSO EM: 12 MAR. 2021. /ASSUNTOS/SAUDE-DE-A-A-Z-1/P/PENTAVALENTE. ACESSO EM: 20 MAR. 2021.

BRASIL. ROTAVÍRUS. DISPONÍVEL EM: HTTPS://WWW.GOV.BR/SAUDE/PTBR/ASSUNTOS/SAUDE-DE-A-A-Z-1/R/ROTAVIRUS. ACESSO EM: 20 MAR.2021.

BRASIL. RUBÉOLA. DISPONÍVEL EM: HTTPS://WWW.GOV.BR/SAUDE/PTBR/ASSUNTOS/SAUDE-DE-A-A-Z-1/R/RUBEOLA. ACESSO EM: 20 MAR. 2021. 
BRASIL. RUBÉOLA: QUAIS OS SINTOMAS, COMO É TRANSMITIDA E COMO PREVENIR. DISPONÍVEL EM: HTTPS://ANTIGO.SAUDE.GOV.BR/SAUDE-DE-AZ/RUBEOLA. ACESSO EM: 21 MAR. 2021.

BRASIL. SARAMPO. DISPONÍVEL EM:HTTP://BVSMS.SAUDE.GOV.BR/DICAS-EMS A U D E / 2114 - S A R A M P O \# : : T EX T = O \% 20 S A R A M P O \%20\%C3\%A9\%20UMA\%20DOEN\%C3\%A7A,CHEGA\%20A\%200\%2C5\%25. ACESSO EM: 21 MAR, 2021.

BRASIL. SARAMPO: SINTOMAS, PREVENÇÃO, CAUSAS, COMPLICAÇÕES E TRATAMENTO. DISPONÍVEL EM: HTTPS://BVSMS.SAUDE.GOV.BR/ULTIMASNOTICIAS/3025-SARAMPO-SINTOMAS-PREVENCAO-CAUSAS-COMPLICACOESE-TRATAMENTO. ACESSO EM: 21 MAR. 2021.

BRASIL. TÉTANO ACIDENTAL: O QUE É, CAUSAS, SINTOMAS, TRATAMENTOS, DIAGNÓSTICO E PREVENÇÃO. DISPONÍVEL EM:HTTPS://ANTIGO. SAUDE.GOV.BR/SAUDE-DE-A-Z/TETANO-ACIDENTAL. ACESSO EM:21 MAR, 2021.

CARVALHO, A. L. D. ET AL. SARAMPO: ATUALIZAÇÕES E REEMERGÊNCIA. REVISTA MÉDICA DE MINAS GERAIS, MINAS GERAIS, P. 80-85, DEZ./2005. DISPONÍVEL EM: HTTP://WWW.RMMG.ORG/EXPORTAR-PDF/2629/V29N13A12.PDF. ACESSO EM: 21 MAR. 2021.

CAVALCANTE, J. R. ET AL. COVID-19 NO BRASIL: EVOLUÇÃO DA EPIDEMIA ATÉ A SEMANA EPIDEMIOLÓGICA 20 DE 2020. EPIDEMIOLOGIA E SERVIÇOS DE SAÚDE, BRASÍLIA, V.29 NO.4, 10 AGO 2020. DOI: HTTPS://DOI.ORG/10.5123/S167949742020000400010. DISPONÍVEL EM: HTTPS://WWW.SCIELOSP.ORG/ ARTICLE/RESS/2020.V29N4/E2020376. ACESSO EM: 14 MAR. 2021.

CDC .EPIDEMIOLOGIA E PREVENÇÃO DE DOENÇAS EVITÁVEIS POR VACINAS. DISPONÍVEL EM: HTTPS://WWW.CDC.GOV/VACCINES/PUBS/ PINKBOOK/HEPB.HTML. ACESSO EM: 20 ABRIL.2021.

CONASEMS. VACINAÇÃO INFANTIL EM DIA. DISPONÍVEL EM: HTTPS://WWW.CONASEMS.ORG.BR/VACINACAO-INFANTIL-EM-DIA/. ACESSO: 10 MAR. 2021.

DATASUS. COBERTURAS VACINAS POR IMUNO SEGUNDO ANO. DISPONÍVELEM: HTTP://TABNET.DATASUS.GOV.BR/CGI/DHDAT.EXE?BD_PNI/CPNIBR.DEF. ACESSO EM 31 DE MARÇO DE 2021.

DÜX, V. O. P. ET AL. DIVERGÊNCIA ENTRE O VÍRUS DO SARAMPO E O VÍRUS DA PESTE BOVINA DATADA DO SÉCULO VI A.C. SCIENCE. V.368, P. 1367-1370, JUN./2020. DOI: 10.1126/SCIENCE.ABA9411. DISPONÍVEL EM: HTTPS://SCIENCE.SCIENCEMAG.ORG/CONTENT/368/6497/1367. ACESSO EM: 21 MAR. 2021. 
FARIA, LINA. POLIOMIELITE: VÁRIAS HISTÓRIAS DA DOENÇA E DE SEUS EFEITOS TARDIOS. SCIELO: HISTÓRIA, CIÊNCIAS, SAÚDE-MANGUINHOS, RIO DE JANEIRO, V. 22, N. 3, JUN/SET 2015. DOI: HTTP://DX.DOI.ORG/10.1590/S010459702015000300026. DISPONÍVEL EM: HTTPS://WWW.SCIELO.BR/ SCIELO.PHP ? SCRIPT=SCI_ARTTEXT\&PID=S 0104 59702015000301081\&LNG=PT\&TLNG=PT. ACESSO EM: 15 DE MAR. DE 2021

FEIJÓ, R. B; SÁFADI, M. A. P. IMUNIZAÇÕES: TRÊS SÉCULOS DE UMA HISTÓRIA DE SUCESSOS E CONSTANTES DESAFIOS. JORNAL DE PEDIATRIA, PORTO ALEGRE, V. 82, N. 3, JUL./2006. DOI: HTTPS://DOI.ORG/10.1590/S002175572006000400001. DISPONÍVEL EM:HTTPS://WWW.SCIELO.BR/SCIELO. PHPSCRIPT $=S C I \_A R T T E X T \& P I D=S 002175572006000400001 \& L N G=P T \& N R M=I$ SO\&TLNG=PT. ACESSO EM:12 MAR. 2021.

FERNANDES, T. M. IMUNIZAÇÃO ANTIVARIÓLICA NO SÉCULO XIX NO BRASIL: INOCULAÇÃO, VARIOLIZAÇÃO, VACINA E REVACINAÇÃO. SCIELO: HISTÓRIA, CIÊNCIAS, SAÚDE-MANGUINHOS, RIO DE JANEIRO, JAN./2003. DOI: HTTPS://DOI.ORG/10.1590/S0104-59702003000500002. DISPONÍVEL EM: HTTPS://WWW.SCIELO.BR/SCIELO.PHP?SCRIPT=SCI_ARTTEXT\&PID=S010459702003000500002\&LNG=PT\&TLNG=PT. ACESSO EM: 12 MAR. 2021.

FIOCRUZ. A REVOLTA DA VACINA. DISPONÍVEL EM : HTTPS://PORTAL.FIOCRUZ.BR/NOTICIA/REVOLTA-DA-VACINA-2. ACESSO EM: 16 MAR. 2021.

FIOCRUZ. AIDS. DISPONÍVEL EM: HTTPS://PORTAL.FIOCRUZ.BR/TAXONOMIAG ER A L - 6 - D O E N C A S / A I D S : : TEX T = A \% $20 \mathrm{~S} \%$ C3\%ADNDROME\%20DE\%20IMUNODEFICI\%C3\%AANCIA\%20ADQUIRIDA,FINAL \%20DA\%20D\%C3\%A9CADA\%20DE\%201980. ACESSO EM: 15 MAR. 2021.

FIOCRUZ. BRASIL APRESENTA AÇÕES DE ERRADICAÇÃO DA POLIOMIELITE. D I S P O N Í V E L E M : H T T P S : / / W W W . B I O . F I O CR U Z . B R / INDEX.PHP/BR/NOTICIAS/987-BRASIL-APRESENTA-ACOES-DE-ERRADICACAODA-POLIOMIELITE. ACESSO EM: 20 MAR. 2021.

FIOCRUZ. BRASIL JÁ POSSUI 8,2 MIL CASOS CONFIRMADOS DE SARAMPO EM 2020. DISPONÍVEL EM: HTTPS://WWW.BIO.FIOCRUZ.BR/ INDEX.PHP/BR/NOTICIAS/2075-BRASIL-JA-POSSUI-8-2-MIL-CASOSCONFIRMADOS-DE-SARAMPO-EM-2020. ACESSO EM: 20 MAR. 2021.

FIOCRUZ. CAXUMBA: SINTOMAS, TRANSMISSÃO E PREVENÇÃO. DISPONÍVEL EM: HTTPS://WWW.BIO.FIOCRUZ.BR/INDEX.PHP/BR/CAXUMBA-SINTOMASTRANSMISSAO-E-PREVENCAO. ACESSO EM: 21 MAR. 2021. 
FIOCRUZ. COMBATE À EPIDEMIA DE H1N1: UM HISTÓRICO DE SUCESSO. DISPONÍVEL EM: HTTPS://CEE.FIOCRUZ.BR/?Q=NODE/1314. ACESSO EM: 20 DE MAR. 2021.

FIOCRUZ. COQUELUCHE: SINTOMAS, TRANSMISSÃO E PREVENÇÃO. DISPONÍVEL EM: HTTPS://WWW.BIO.FIOCRUZ.BR/INDEX.PHP/ BR/COQUELUCHE-SINTOMAS-TRANSMISSAO-E-PREVENCAO. ACESSO EM: 21 MAR. 2021.

FIOCRUZ. DIFTERIA: SINTOMAS, TRANSMISSÃO E PREVENÇÃO. DISPONÍVEL EM: HTTPS://WWW.BIO.FIOCRUZ.BR/INDEX.PHP/BR/DIFTERIA-SINTOMASTRANSMISSAO-E-PREVENCAO. ACESSO EM: 21 MAR. 2021.

FIOCRUZ. FEBRE AMARELA: SINTOMAS, TRANSMISSÃO E PREVENÇÃO. DISPONÍVEL EM: HTTPS://WWW.BIO.FIOCRUZ.BR/INDEX.PHP/BR/FEBREAMARELA-SINTOMAS-TRANSMISSAO-E-PREVENCAO. ACESSO EM: 20 MAR. 2021.

FIOCRUZ. HISTÓRIA E QUALIDADE: PRODUÇÃO DA VACINA CONTRA FEBRE AMARELA NA FIOCRUZ. DISPONÍVEL EM: HTTPS://PORTAL.FIOCRUZ.BR/ NOTICIA/HISTORIA-E-QUALIDADE-PRODUCAO-DA-VACINA-CONTRA-FEBREAMARELA-NA-FIOCRUZ. ACESSO EM: 21 MAR. 2021.

FIOCRUZ. INSTITUTO NACIONAL DE CONTROLE DE QUALIDADE EM SAÚDE. DISPONÍVEL EM:HTTPS://WWW.INCQS.FIOCRUZ.BR/INDEX. PHPOPTION=COM_CONTENT\&VIEW=ARTICLE\&ID=1721:A-IMPORTANCIA-DAVACINACAO-NAO-ESTA-SOMENTE-NA-PROTECAO-INDIVIDUAL-MAS-PORQUEELA-EVITA-A-PROPAGACAO-EM-MASSA-DE-DOENCAS-QUE-PODEM-LEVAR-AMORTE-OU-A-SEQUELAS-GRAVES\&CATID=42\&ITEMID=132. ACESSO EM: 12 MAR. 2021.

FIOCRUZ. LINHA DO TEMPO: VACINAÇÃO NO BRASIL. DISPONÍVEL EM: HTTPS://RADIS.ENSP.FIOCRUZ.BR/INDEX.PHP/HOME/REPORTAGEM/LINHADO-TEMPO-VACINACAO-NO-BRASIL. ACESSO EM:14 ABR. 2021.

FIOCRUZ. MONITORA COVID-19. DISPONÍVEL EM: HTTPS://BIGDATACOVID19.ICICT.FIOCRUZ.BR/. ACESSO EM: 23 MAR. 2021.

FIOCRUZ. O QUE É UMA PANDEMIA. DISPONÍVEL EM: HTTPS://WWW.BIO.FIOCRUZ.BR/INDEX.PHP/BR/NOTICIAS/1763OQUEEUMAP ANDEMIA\#: :TEXT=SEGUNDO\%20A\%20ORGANIZA\%C3\%A7\%C3\%A3O\%2C\%2 OPANDEMIA\%20\%C3\%A9,SUSTENTADA\%20DE\%20PESSOA\%20PARA\%20PESS OA. ACESSO EM: 15 MAR. 2021.

FIOCRUZ. OS ÚLTIMOS DIAS DA VARÍOLA. DISPONÍVEL EM: HTTPS://AGENCIA. FIOCRUZ.BR/SITES/AGENCIA.FIOCRUZ.BR/FILES/REVISTAMANGUINHOSMATERIAP DF/RM8PAG44A45FIODAHISTORIA.PDF. ACESSOEM:20MAR. 2021. 
FIOCRUZ. PANDEMIA DE GRIPE DE 1918. DISPONÍVEL EM: HTTP://WWW.INVIVO.FIOCRUZ.BR/CGI/CGILUA.EXE/SYS/START.HTM?INFOID $=815 \&$ SID $=7$. ACESSO EM: 10 MAR. 2021.

FIOCRUZ. PROCESSO DE DESENVOLVIMENTO DE VACINAS É DESTAQUE NA REVISTA RADIS. DISPONÍVEL EM: HTTPS://PORTAL.FIOCRUZ.BR/ NOTICIA/PROCESSO-DE-DESENVOLVIMENTO-DE-VACINAS-E-DESTAQUE-NAREVISTA-RADIS. ACESSO EM: 22 MAR. 2021.

FIOCRUZ. RUBÉOLA: SINTOMAS, TRANSMISSÃO E PREVENÇÃO. DISPONÍVEL EM: HTTPS://WWW.BIO.FIOCRUZ.BR/INDEX.PHP/BR/RUBEOLA-SINTOMASTRANSMISSAO-E-PREVENCAO. ACESSO EM: 21 MAR. 2021.

FIOCRUZ. TÉTANO: SINTOMAS, TRANSMISSÃO E PREVENÇÃO. DISPONÍVEL EM: HTTPS://WWW.BIO.FIOCRUZ.BR/INDEX.PHP/BR/TETANO-SINTOMASTRANSMISSAO-E-PREVENCAO. ACESSO EM: 21 MAR. 2021.

FIOCRUZ. UMA BREVE HISTÓRIA DA FEBRE AMARELA. DISPONÍVEL EM: HTTPS://AGENCIA.FIOCRUZ.BR/UMA-BREVE-HIST\%C3\%B3RIA-DA-FEBREAMARELA. ACESSO EM: 21 MAR. 2021.

FIOCRUZ. VACINA PNEUMOCÓCICA COMPLETA 10 ANOS NO BRASIL. DISPONÍVEL E M : HTTPS: / / W W W. BIO.FIOCRUZ. BR / INDEX.PHP/BR/NOTICIAS/1626-VACINA-PNEUMOCOCICA-COMPLETA-10ANOS-NO-BRASIL. ACESSO EM: 20 MAR. 2021.

FONSECA, J. C. F. HISTÓRICO DAS HEPATITES VIRAIS. REVISTA DA SOCIEDADE BRASILEIRA DE MEDICINA TROPICAL, UBERABA, VOL.43 NO.3, MAI./JUN. 2010. DOI: HTTPS://DOI.ORG/10.1590/S0037-86822010000300022. DISPONÍVEL EM: HTTPS://WWW.SCIELO.BR/SCIELO.PHP?SCRIPT=SCI_ARTTEXT\&PID=S003786822010000300022. ACESSO EM: 21 MAR. 2021.

FORATTINI, O. P. AIDS E SUA ORIGEM. REVISTA DE SAÚDE PÚBLICA, V.27, N.3, SÃO PAULO, JUN./1993. DOI: HTTPS://DOI.ORG/10.1590/S003489101999300003000001 . D I S P O N Í VE L E M : HTTPS://WWW.SCIELO.BR/SCIELO.PHP?SCRIPT=SCI_ARTTEXT\&PID=S003489101993000300001\&LNG=PT\&TLNG=PT. ACESSO EM: 20 MAR. 2021.

FRANCO, B. D. G. M. ALIMENTOS, SARS-COV-2 E COVID-19: CONTATO POSSÍVEL, TRANSMISSÃO IMPROVÁVEL. ESTUDOS AVANÇADOS, V.34 NO.100. SÃO PAULO, SET/DEZ, 2020. DOI: HTTPS://DOI.ORG/10.1590/S0103-4014.2020.34100.012. DISPONÍVEL EM: HTTPS://WWW.SCIELO.BR/SCIELO.PHP?SCRIPT= SCI_ARTTEXT\&PID=S0103-40142020000300189. ACESSO EM: 14 MAR. 2021. 
GDF. POLIOMIELITE. DISPONÍVEL EM: HTTP://WWW.SAUDE.DF. GOV.BR/POLIOMIELITE/. ACESSO EM 31 DE MARÇO DE 2021.

FIGUEIREDO F. HISTÓRICO DE VACINAS. DIREÇÃO DE FELIPE FIGUEIREDO. REALIZAÇÃO DE FELIPE FIGUEIREDO. ROTEIRO: FELIPE FIGUEIREDO. 2021. 1 (853 MIN.), SON., COLOR. DISPONÍVEL EM: HTTPS://WWW.YOUTUBE.COM/ WATCH?V=ENTTRLQ3ZMG. ACESSO EM: 12 MAR. 2021.

HOCHMAN, GILBERTO. VACINAÇÃO, VARÍOLA E UMA CULTURA DA IMUNIZAÇÃO NO BRASIL. SCIELO: CIÊNCIA E SAÚDE COLETIVA, RIO DE JANEIRO, V. 16, N. 2, P. 1-12, DEZ./2005. DOI: HTTPS://DOI.ORG/10.1590/S141381232011000200002. DISPONÍVEL EM: HTTPS://WWW.SCIELO.BR/ SCIELO.PHP?SCRIPT=SCI_ARTTEXT\&PID=S1413-81232011000200002. ACESSO EM: 20 MAR.2021.

HOSPITAL ALEMÃO OSWALDO CRUZ. HÁ 40 ANOS A VARÍOLA ERA ERRADICADA DO PLANETA. DISPONÍVEL EM: HTTPS://WWW. HOSPITAL OSWALDOCRUZ.ORG.BR/IMPRENSA/NOTICIAS/HA-40-ANOS-A-VARIOLA-ERAERRADICADA-DO-PLANETA. ACESSO EM: 15 MAR. 2021.

IBGE. TÁBUA COMPLETA DE MORTALIDADE PARA O BRASIL - 2019 BREVE ANÁLISE DA EVOLUÇÃO DA MORTALIDADE NO BRASIL. DISPONÍVEL EM: HTTPS://BIBLIOTECA.IBGE.GOV.BR/VISUALIZACAO/PERIODICOS/3097/TCMB_ 2019.PDF. ACESSO EM: 31 MAR. 2021.

ISER, B. P. M. ET AL. DEFINIÇÃO DE CASO SUSPEITO DA COVID-19: UMA REVISÃO NARRATIVA DOS SINAIS E SINTOMAS MAIS FREQUENTES ENTRE OS CASOS CONFIRMADOS. EPIDEMIOLOGIA E SERVIÇOS DE SAÚDE, BRASÍLIA, V. 29, N. 3, P. 1-11, DEZ./2005. DOI: HTTP://DX.DOI.ORG/10.5123/S167949742020000300018. DISPONÍVEL EM: HTTPS://WWW.SCIELO.BR/ SCIELO.PHP?SCRIPT=SCI_ARTTEXT\&PID $=S 2237-96222020000300401 \#:$ : TEXT=0\%20ESPECTRO\%20DA\%20DOEN\%C3\%A7A\%20CL\%C3\%ADNICA,A\%20 DISPNEIA\%20FOI\%2OFREQUENTE\%20ENTRE. ACESSO EM: 14 MAR.2021.

LAROCCA, L. M; CARRARO, T.E. O MUNDO DAS VACINAS - CAMINHOS (DES)CONHECIDOS. COGITARE ENFERMAGEM, CURITIBA, V.5, N.2. P.43-50. JUL/DEZ, 2000.

DISPONÍVEL EM: HTTPS://REVISTAS.UFPR.BR/COGITARE/ARTICLE/ VIEW/44884. ACESSO EM:12 MAR. 2021.

LEVI, G. C. RECUSA DAS VACINAS: CAUSAS E CONSEQUÊNCIAS. SÃO PAULO: SEGMENTO FARMA, 2013. P.03 DISPONÍVEL EM: HTTPS://SBIM.ORG.BR/ PUBLICACOES/LIVROS77-RECUSA-DE-VACINAS-CAUSAS-E-CONSEQUENCIAS. ACESSO EM:14 DE MAR. DE 2021 
LEVI, G. C.; KALLAS, E. G. VARÍOLA, SUA PREVENÇÃO VACINAL E AMEAÇA COMO AGENTE DE BIOTERRORISMO. REVISTA DA ASSOCIAÇÃO MEDICA BRASILEIRA, SÃO PAULO, V. 48, N. 4, P. 357-362, DEC. 2002. DISPONIVEL EM: HTTP://WWW.SCIELO.BR/SCIELO.PHP?SCRIPT=SCI_ARTTEXT\&PID=S010442302002000400045\&LNG=EN\&NRM=ISO. ACESSO EM: 15 MAR. 2021. HTTPS://DOI.ORG/10.1590/S0104-42302002000400045.

LIMA, C. M. A. O. INFORMAÇÕES SOBRE O NOVO CORONAVÍRUS (COVID-19). RADIOLOGIA BRASILEIRA, SÃO PAULO, VOL. 53, NO.2, MAR/ABR/2020. DOI: HTTP://DX.DOI.ORG/10.1590/0100-3984.2020.53.2E1. DISPONÍVEL EM: HTTPS://WWW.SCIELO.BR/SCIELO.PHP?PID=S0100-39842020000 200001\&SCRIPT=SCI_ARTTEXT\&TLNG=PT. ACESSO EM:14 MAR. 2021.

LIMA, S. C. EM TEMPOS DE PANDEMIA, HYGEIA LEMBRA A GRIPE ESPANHOLA. HYGEIA: REVISTA BRASILEIRA DE GEOGRAFIA MÉDICA E DA SAÚDE, V. 5, N. 8, 4 OUT./ 2009. DISPONÍVEL EM: HTTP://WWW.SEER.UFU.BR/INDEX.PHP/ HYGEIA/ARTICLE/VIEW/16943. ACESSO EM: 15 MAR. 2021.

LUIZ, A. C. G. R. ET AL. MOVIMENTO ANTIVACINA: A PROPAGAÇÃO DE UMA DISTOPIA QUE AMEAÇA A SAÚDE DA POPULAÇÃO BRASILEIRA. BRAZILIAN JOURNAL OF HEALTH REVIEW, V. 4, N. 1, P. 430-441, 2021. DISPONÍVEL EM: HTTPS://WWW.BRAZILIANJOURNALS.COM/INDEX.PHP/BJHR/ARTICLE/VIEW/ 22731/18216 ACESSO EM: 13 DE MAR. DE 2021

LUZ, D. C. R. P. ET AL. MOVIMENTO ANTIVACINAÇÃO: UMA AMEAÇA À HUMANIDADE. REVISTA E-CIÊNCIA, V.7, NO. 2, 2019. DOI: HTTP://DX.DOI.ORG/10.19095/REC.V7I2.885. DISPONÍVEL EM: HTTP://WWW.REVISTAFJN.COM.BR/REVISTA/INDEX.PHP/ECIENCIA/ARTICLE/V IEW/885. ACESSO EM: 12 MAR. 2021.

MANUAL MSD VERSÃO SAÚDE PARA A FAMÍLIA. CRONOGRAMA DE VACINAÇÃO NA INFÂNCIA. DISPONÍVEL EM: HTTPS://WWW.MSDMANUALS.COM/PTBR/CASA/PROBLEMAS-DE-SA\%C3\%BADE-INFANTIL/VACINA\%C3\%A7\%C3\% A3O-DE-CRIAN\%C3\%A7AS/CRONOGRAMA-DE-VACINA\%C3\%A7\%C3\%A3O-NAINF\%C3\%A2NCIA. ACESSO EM: 12 MAR. 2021.

MANUAL MSD. GRIPE H1N1 PANDÊMICA (GRIPE SUÍNA). DISPONÍVEL EM: HTTPS://WWW.MSDMANUALS.COM/PT-BR/CASA/INFEC\%C3\%A7\% C 3\%B 5ES/V\%C3\%ADRUS-RESPIRAT\%C3\%B 3RIOS/GRIPE-H1N 1 PAND\%C3\%AAMICA-GRIPE-SU\%C3\%ADNA. ACESSO EM: 23 MAR. 2021.

SÁFADI. M. A. P, BARROS. A. P. VACINAS MENINGOCÓCICAS CONJUGADAS: EFICÁCIA E NOVAS COMBINAÇÕES. JORNAL DE PEDIATRIA, V. 82, N.3, P. 10, 2006. DOI: HTTPS://DOI.ORG/10.1590/S0021-75572006000400005. 
DISPONÍVEL EM: HTTPS://WWW.SCIELO.BR/SCIELO.PHP?SCRIPT= SCI_ARTTEXT\&PID=S0021-75572006000400005\&LNG =PT\&NRM = ISO\&TLNG=PT. ACESSO EM: 20 MAR. 2021.

MDS. SAÚDE. HEPATITE B- SINTOMAS, PREVENÇÃO E VACINA. DISPONÍVEL EM:HTTPS://WWW.MDSAUDE.COM/GASTROENTEROLOGIA/HEPATITEB/\#O_QUE_E_A_HEPATITE_B. ACESSO EM:20 MAR. 2021.

MEU CALENDÁRIO DE VACINAS. DTP/DTPA CALENDÁRIO DE VACINAÇÃO RECOMENDADO. DISPONÍVEL EM: HTTPS://MEUCALENDARIODE VACINAS.COM.BR/EDUCACAO/DTP-DTPA/. ACESSO EM: 20 MAR. 2021.

MORAES, ET AL. EVENTOS ADVERSOS DE VACINAS E AS CONSEQUÊNCIAS DA NÃO VACINAÇÃO: UMA ANÁLISE CRÍTICA. REVISTA DE SAÚDE PÚBLICA, SÃO PAULO, P.1-13, 2018. DISPONÍVEL EM: HTTPS://WWW.SCIELO.BR/ PDF/RSP/V52/PT_0034-8910-RSP-S1518-87872018052000384.PDF. ACESSO EM: 21 MAR. 2021.

NETTO, E. J. R. ET AL. AVALIAÇÃO DO CONTROLE DA QUALIDADE REALIZADO NOS PRODUTOS VACINAIS PARA SARAMPO, CAXUMBA E RUBÉOLA UTILIZADOS NO PROGRAMA NACIONAL DE IMUNIZAÇÕES DO BRASIL NO PERÍODO DE 1999 A 2007. REVISTA DO INSTITUTO DO ADOLFO LUTZ, SÃO PAULO, V. 69, №3, P.408415, 2010. DISPONÍVEL EM: HTTP://PERIODICOS.SES.SP.BVS.BR/ SCIELO.PHP?SCRIPT $=S C I \_A R T T E X T \& P I D=S 0073-98552010000$ 300019\&LNG=P\&NRM=ISO. ACESSO EM: 21 MAR. 2021.

OLIVEIRA, E. C. A EPIDEMIA DE VARÍOLA E O MEDO DA VACINA EM GOIÁS. HISTÓRIA, CIÊNCIAS, SAÚDE - MANGUINHOS, RIO DE JANEIRO V.20, N.3, P.939962, JUL./SET. 2013. DISPONÍVEL EM: HTTPS://DOI.ORG/10.1590/S0104597020130003000011. ACESSO EM: 15 MAR. 2021.

OLIVEIRA, W. K. ET AL. COMO O BRASIL PODE DETER A COVID-19. EPIDEMIOLOGIA E SERVIÇOS DE SAÚDE, BRASÍLIA, V.29 NO.2 P.1-8, 2020. DOI: 10.5123 /S1679-49742020000200023. DISPONÍVEL EM : HTTP://SCIELO.IEC.GOV.BR/SCIELO.PHP?SCRIPT=SCI_ARTTEXT\&PID=S167949742020000200002. ACESSO EM: 14 MAR. 2021.

OSTI, C.; MACHADO, J. M. VÍRUS DA HEPATITE B: AVALIAÇÃO DA RESPOSTA SOROLÓGICA À VACINA EM FUNCIONÁRIOS DE LIMPEZA DE HOSPITAL - ESCOLA. CIÊNCIA E SAÚDE COLETIVA, SÃO PAULO, P.1343-1348, 2010. DISPONÍVEL EM: HTTPS://SCIELOSP.ORG/PDF/CSC/2010.V15SUPPL1/1343-1348. ACESSO EM: 21 MAR. 2021. 
PARKER, R.; CAMARGO JR, K. R. POBREZA E HIV/AIDS: ASPECTOS ANTROPOLÓGICOS E SOCIOLÓGICOS. CADERNOS DE SAÚDE PÚBLICA, RIO DE JANEIRO, VOL.16(SUP.1), P.89-102, 2000. DOI: 10.1590/S0102311X2000000700008. DISPONÍVEL EM: HTTPS://WWW.SCIELO.BR/ SCIELO.PHP?SCRIPT $=S C I$ ARTTEXT\&PID $=S 0102-311 \times 20000007$ 00008\&LNG=PT\&TLNG=PT. ACESSO EM: 18 MAR. 2021.

PINTO, A. C. S. ET AL. COMPREENSÃO DA PANDEMIA DA AIDS NOS ÚLTIMOS 25 ANOS. DTS - JORNAL BRASILEIRO DE DOENÇAS SEXUALMENTE TRANSMISSÍVEIS, V. 19, N. 1, P. 1-6, DEZ./2005. DISPONÍVEL EM: HTTP://WWW.DST.UFF.BR/ REVISTA19-1-2007/7.PDF. ACESSO EM:20 MAR. 2021.

FIOCRUZ. HISTÓRIA E QUALIDADE: PRODUÇÃO DA VACINA CONTRA FEBRE AMARELA NA FIOCRUZ. DISPONÍVEL EM: HTTPS://PORTAL.FIOCRUZ.BR/ NOTICIA/HISTORIA-E-QUALIDADE-PRODUCAO-DA-VACINA-CONTRA-FEBREAMARELA-NA-FIOCRU. ACESSO EM: 21 MAR, 2021.

PRESTES A, F, R, O. AVALIAÇÃO DE ADJUVANTES EM NOVAS FORMULAÇÕES DE VACINA TRÍPLICE BACTERIANA [DISSERTAÇÃO], SÃO PAULO: INSTITUTO BUTANTÃ, UNIVERSIDADE DE SÃO PAULO; 2009. DISPONÍVEL EM: HTTPS://WWW.TESES.USP.BR/TESES/DISPONIVEIS/87/87131/TDE-28042009111641/PUBLICO/ANAFABIOLAROLLOOLIVEIRAPRESTES_MESTRADO.PDF. ACESSO EM: 21 MAR. 2021.

REVISTA DA VACINA. CAMPANHAS DE VACINAÇÃO.2017 DISPONÍVEL EM: HTTP://WWW.CCMS.SAUDE.GOV.BR/REVOLTA/CAMPANHAS.HTML. ACESSO EM: 12 MAR. 2021.

REVISTA GALILEU. PESTE BUBÔNICA, 5 PONTOS PARA ENTENDER O QUE É A DOENÇA. DISPONÍVEL EM: HTTPS://REVISTAGALILEU.GLOBO.COM/CIENCIA/ SAUDE/NOTICIA/2020/07/PESTE-BUBONICA-5-PONTOS-PARA-ENTENDER-OQUE-E-DOENCA.HTML. ACESSO EM: 22 MAR. 2021.

SARAIVA, L. J. C; FARIA, J. F. A CIÊNCIA E A MÍDIA: A PROPAGAÇÃO DE FAKE NEWS E SUA RELAÇÃO COM O MOVIMENTO ANTIVACINA NO BRASIL. REVISTA BRASILEIRA DE CIÊNCIAS DA COMUNICAÇÃO, BELÉM - PA, 2019. DISPONÍVEL EM: HTTPS://PORTALINTERCOM.ORG.BR/ANAIS/NACIONAL2019/RESUMOS/ R14-1653-1.PDF. ACESSO EM:20 MAR. 2021

SBP. EM REPORTAGEM DO FANTÁSTICO, ESPECIALISTAS DA SBP CONCLAMAM A POPULAÇÃO A IMUNIZAR CRIANÇAS E ADOLESCENTES. 2018 DISPONÍVEL EM: HTTPS://WWW.SBP.COM.BR/IMPRENSA/DETALHE/NID/EM-REPORTAGEMDO-FANTASTICO-ESPECIALISTAS-DA-SBP-CONCLAMAM-A-POPULACAO-AIMUNIZAR-CRIANCAS-E-ADOLESCENTES/. ACESSO EM: 14 MAR. 2021. 
SECRETARIA DA SAÚDE DO PARANÁ. HEPATITES VIRAIS. DISPONÍVEL EM: HTTPS://WWW.SAUDE.PR.GOV.BR/PAGINA/HEPATITES-VIRAIS\#. ACESSO EM: 20 MAR. 2021.

SECRETARIA DE ESTADO DE SAÚDE DE SÃO PAULO. RUBÉOLA: SITUAÇÃO EPIDEMIOLÓGICA E MEDIDAS DE CONTROLE. BEPA, BOL. EPIDEMIOL. PAUL. (ONLINE), SÃO PAULO, V. 4, N. 48, DEZ. 2007. DISPONÍVEL EM: HTTP://PERIODICOS.SES.SP.BVS.BR/SCIELO.PHP?SCRIPT=SCI_ARTTEXT\&PID=S 1806-42722007001200001\&LNG=PT\&NRM=ISO. ACESSO EM: 21 MAR. 2021.

SECRETARIA DE ESTADO DA SAÚDE DO ESTADO DE SÃO PAULO. VACINA CONTRA O ROTAVÍRUS. REVISTA DE SAÚDE PÚBLICA, SÃO PAULO, V. 40, N. 2, P. 1-4, ABR/2006. DOI: HTTPS://DOI.ORG/10.1590/S0034-89102006000200026. D I S P O N Í VEL E M : H T T P S : / / W W W. S CIELO . B R / SCIELO.PHP?SCRIPT=SCI_ARTTEXT\&PID=S0034-89102006000200026. ACESSO EM: 13 DE MAR. DE 2021.

SECRETÁRIA DE SAÚDE DO DISTRITO FEDERAL. COQUELUCHE. DISPONÍVEL EM: HTTP://WWW.SAUDE.DF.GOV.BR/COQUELUCHE/. ACESSO EM: 21 MAR. 2021.

SECRETÁRIA DE SAÚDE DO DISTRITO FEDERAL. POLIOMIELITE. DISPONÍVEL EM: HTTP://SAUDE.DF.GOV.BR/POLIOMIELITE/. ACESSO EM: 21 MAR. 2021.

SECRETÁRIA DE SAÚDE DO DISTRITO FEDERAL. TUBERCULOSE ESTÁ ENTRE AS DEZ MAIORES CAUSAS DE MORTES NO MUNDO. DISPONÍVEL EM: HTTP://WWW.SAUDE.DF.GOV.BR/TUBERCULOSE-ESTA-ENTRE-AS-DEZCAUSAS-DE-MORTES-NO-MUNDO/. ACESSO EM: 21 MAR. 2021.

SILVA, D. M. O TÉTANO COMO DOENÇA DE BASE PARA DISFAGIA. REVISTA CEFAC, V.12, NO.3, MAI/JUN, 2010. DOI: HTTPS://DOI.ORG/10.1590/S1516184620010000003000018 . D I S P O N Í VE L E M : HTTPS://WWW.SCIELO.BR/SCIELO.PHP?SCRIPT=SCI_ARTTEXT\&PID=S151618462010000300018. ACESSO EM: 21 MAR. 2021.

SILVA, R. S. U. ET AL. PREVALÊNCIA DA INFECÇÃO PELO VÍRUS DA HEPATITE B EM UM MUNICÍPIO DO INTERIOR DO ESTADO DO ACRE. REVISTA PAN-AMAZÔNICA DE SAÚDE, AMAZÔNIA OCIDENTAL, BRASIL, V. 8, NO. 3, SET., 2017. DISPONÍVEL EM: HTTP://SCIELO.IEC.GOV.BR/SCIELO.PHP?SCRIPT=SCI_ARTTEXT\&PID= S2176-62232017000300019. ACESSO EM:21 MAR. 2021.

SÍRIO-LIBANÊS. VACINA CONTRA ROTAVÍRUS. DISPONÍVEL EM: HTTPS://HOSPITALSIRIOLIBANES.ORG.BR/HOSPITAL/ESPECIALIDADES/CENTROIMUNIZACOES/PAGINAS/VACINA-ROTAVIRUS.ASPX. ACESSO EM: 15 ABR. 2021. 
SOUSA, C. J; VIGO, Z. L; PALMEIRA C. S. COMPREENSÃO DOS PAIS ACERCA DA IMPORTÂNCIA DA VACINAÇÃO INFANTIL. REVISTA ENFERMAGEM CONTEMPORÂNEA, SALVADOR, V.1, N.1, P. 15, DEZEMBRO 2012. ISSN 23173378. DOI: HTTP://DX.DOI.ORG/10.17267/2317-3378REC.V1I1.39. ACESSO 21 MAR. 2021.

SOUZA T. DOS S.; COELHOE. G. DE A.; OLIVEIRA T. R. S. DE; E SANTOS J. C. DA S.; BARROS P. B. F. OCORRÊNCIA DE FEBRE AMARELA NO BRASIL: UMA REVISÃO INTEGRATIVA DA LITERATURA (2014-2018). REVISTA ELETRÔNICA ACERVO SAÚDE, N. 28, P. E896, 13 AGO. 2019. D.O.I: HTTPS://DOI.ORG/ 10.25248/REAS.E896.2019. ACESSO 18 ABR. 2021.

TAB. TESTADA EM ANIMAIS, VACINA CONTRA COVID-19 DIVIDE OPINIÕES ENTRE VEGANOS. DISPONÍVEL EM: HTTPS://TAB.UOL.COM.BR/NOTICIAS/REDACAO/ 2021/03/17/TESTADA-EM-ANIMAIS-VACINA-CONTRA-COVID-19-DIVIDEOPINIOES-ENTRE-VEGANOS.HTML. ACESSO EM: 15 DE MAR DE 2021

TABORDA, A. C. D. CAXUMBA: ASPECTOS DE UMA EPIDEMIA. UNIVERSIDADE FEDERAL DA FRONTEIRA SUL. 2018 . DISPONÍVEL EM: HTTPS://RD.UFFS.EDU.BR/BITSTREAM/PREFIX/3088/1/AMANDA\%20CAROLIN E\%20DAMAS\%20TABORDA.PDF. ACESSO EM: 21 MAR. 2021.

TEMPORÃO, J, G. O PROGRAMA NACIONAL DE IMUNIZAÇÕES (PNI): ORIGENS E DESENVOLVIMENTO. HISTÓRIA, CIÊNCIAS, SAÚDE - MANGUINHOS, RIO DE JANEIRO, VOL. 10 (SUPLEMENTO 2), P. 1-17, 2003. DOI: HTTPS://DOI.ORG/10.1590/S0104-59702003000500008. DISPONÍVEL EM: HTTPS://WWW.SCIELO.BR/SCIELO.PHP?SCRIPT=SCI_ARTTEXT\&PID=S010459702003000500008. ACESSO EM: 14 DE MAR. DE 2021

TOLEDO, A. C. C. JR. HISTÓRIA DA VARÍOLA, REVISTA MÉDICA DE MINAS GERAIS, BELO HORIZONTE - MINAS GERAIS, VO.15, 1; FEV. 2004. DISPONÍVEL EM: HTTP://RMMG.ORG/ARTIGO/DETALHES/1461\#. ACESSO EM: 22 MAR. 2021.

UNAIDS. ESTATÍSTICAS. DISPONÍVEL EM: HTTPS://UNAIDS.ORG.BR/ ESTATISTICAS/. ACESSO EM: 13 MAR. 2021.

UNASUS. CORONAVÍRUS: EM QUE PÉ ESTÃO AS 6 VACINAS, MAIS ADIANTADAS CONTRA A COVID-19. DISPONÍVEL EM: HTTPS://WWW.UNASUS.GOV.BR/ NOTICIA/CORONAVIRUS-EM-QUE-PE-ESTAO-AS-6-VACINAS-MAISADIANTADAS-CONTRA-A-COVID-19. ACESSO EM: 22 MAR. 2021.

UOL. A PESTE NEGRA. DISPONÍVEL EM: HTTPS://DRAUZIOVARELLA. UOL.COM.BR/DRAUZIO/A-PESTE-NEGRA-ARTIGO/. ACESSO EM:15 MAR. 2021. 
UOL. GRIPE H1N1 (GRIPE SUÍNA). DISPONÍVEL EM: HTTPS://DRAUZIOVARELLA. UOL.COM.BR/DOENCAS-E-SINTOMAS/GRIPE-H1N1-GRIPE-SUINA/. ACESSO EM: 20 MAR. 2021.

UOL. PRAGA DE JUSTINIANO: A PRIMEIRA PANDEMIA DA HISTÓRIA. AVENTURAS NA HISTÓRIA. DISPONÍVEL EM: HTTPS://AVENTURASNAHISTORIA. UOL.COM.BR/AMP/NOTICIAS/REPORTAGEM/PRAGA-DE-JUSTINIANO-APRIMEIRA-PANDEMIA-DA-HISTORIA.PHTML. ACESSO EM: 15 MAR. 2021.

UOL. VACINAS CONTRA A COVID-19 ENTENDA A DIFERENÇA ENTRE 5 DELAS. DISPONÍVEL EM: HTTPS://WWW.UOL.COM.BR/VIVABEM/NOTICIAS/ REDACAO/2021/02/03/VACINAS-CONTRA-COVID-19-ENTENDA-A-DIFERENCAENTRE-ELAS.HTM. ACESSO EM: 22 MAR. 2021.

VANIFAS R. ET AL. HISTÓRIA 3 - O MUNDO POR UM FIO: DO SÉCULO XX AO XXI. 2a ED. SÃO PAULO: SARAIVA, 2013. P. 23-24.

VARELLA, D. VACINA. DISPONÍVEL EM: HTTPS://DRAUZIOVARELLA. UOL.COM.BR/INFECTOLOGIA/VACINA/. ACESSO EM: 12 MAR. 2021

VASCONCELOS, E.P.; LARA, C.A.S. MOVIMENTO ANTIVACINA: A DISSEMINAÇÃO DE UMA ILUSÃO. ANAIS DO IV CONLUBRADEC, V. 4, N. 31, CURITIBA, 2019. P. 121-124.

XAVIER, A. R. ET AL. DIAGNÓSTICO CLÍNICO, LABORATORIAL E PROFILÁTICO DO SARAMPO NO BRASIL. JORNAL BRASILEIRO DE PATOLOGIA E MEDICINA LABORATORIAL, RIO DE JANEIRO, VOL.55 NO.4, JUL/AGO, 2019. DISPONÍVEL E M : H T T P S : / / W W W. S CIELO. BR / S CIE LO. P H P ? PID = S167624442019000400390\&SCRIPT=SCI_ARTTEXT\&TLNG=PT\#: :TEXT=A\%20F ASE\%20DE\%2OINCUBA\%C3\%A7\%C3\%A3O\%20DURA,\%2C\%20TOSSE\%2C\%20C ORIZA\%20E\%20CONJUNTIVITE. ACESSO EM: 21 MAR. 2021. 



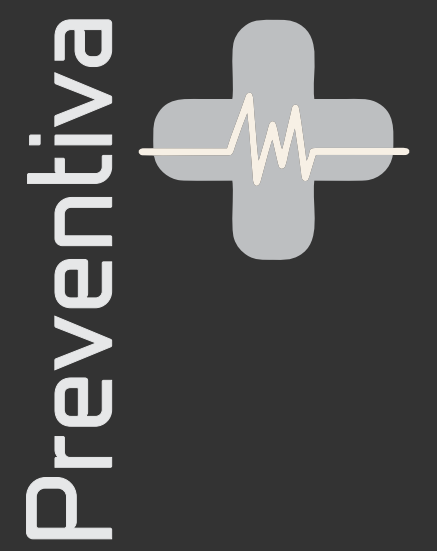

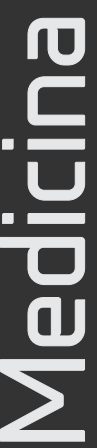

https://www.facebook.com/Synapse-Editora-111777697257115

(0) https://www.instagram.com/synapseeditora

in https://www.linkedin.com/in/synapse-editora-compartilhando-conhecimento/ 31 98264-1586

editorasynapse@gmail.com

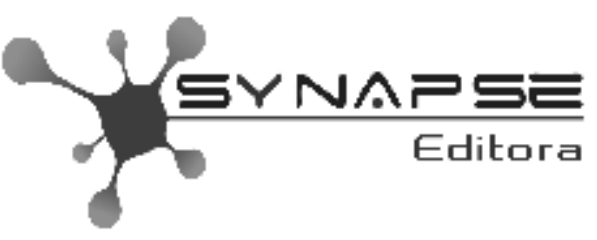

Compartilhando conhecimento 